\title{
Effect of the Quasi-Petal Heat Transfer Tube on the Melting Process of the Nano-Enhanced Phase Change Substance in a Thermal Energy Storage Unit
}

\author{
Mohammad Ghalambaz ${ }^{1,2}$, , Seyed Abdollah Mansouri Mehryan ${ }^{3}\left(\mathbb{D}\right.$, Reza Kalantar Feeoj $^{4}(\mathbb{D})$, Ahmad Hajjar $^{5}$, \\ Obai Younis ${ }^{6,7}$, Pouyan Talebizadehsardari ${ }^{1,2, *(\mathbb{D})}$ and Wahiba Yaïci ${ }^{8, *(D)}$
}

Citation: Ghalambaz, M.; Mehryan, S.A.M.; Feeoj, R.K.; Hajjar, A.; Younis, O.; Talebizadehsardari, P.; Yaïci, W. Effect of the Quasi-Petal Heat Transfer Tube on the Melting Process of the Nano-Enhanced Phase Change Substance in a Thermal Energy Storage Unit. Sustainability 2021, 13, 2871. https://doi.org/10.3390/ su13052871

Academic Editor: Vasileios C. Kapsalis

Received: 26 January 2021

Accepted: 1 March 2021

Published: 7 March 2021

Publisher's Note: MDPI stays neutral with regard to jurisdictional claims in published maps and institutional affiliations.

Copyright: (c) 2021 by the authors. Licensee MDPI, Basel, Switzerland This article is an open access article distributed under the terms and conditions of the Creative Commons Attribution (CC BY) license (https:// creativecommons.org/licenses/by/ $4.0 /)$.
1 Metamaterials for Mechanical, Biomechanical and Multiphysical Applications Research Group, Ton Duc Thang University, Ho Chi Minh City 758307, Vietnam; mohammad.ghalambaz@tdtu.edu.vn

2 Faculty of Applied Sciences, Ton Duc Thang University, Ho Chi Minh City 758307, Vietnam

3 Young Researchers and Elite Club, Yasooj Branch, Islamic Azad University, Yasooj 75914-93686, Iran; alal171366244@gmail.com

4 Department of Mechanical Engineering, Shahrekord University, Shahrekord 88186-34141, Iran; rezakalantar.mech@gmail.com

5 ECAM Lyon, LabECAM, Université de Lyon, 69005 Lyon, France; ahmad.hajjar@ecam.fr

6 Department of Mechanical Engineering, College of Engineering at Wadi Addwaser, Prince Sattam Bin Abdulaziz University, Wadi Addwaser 11991, Saudi Arabia; oubeytaha@hotmail.com

7 Department of Mechanical Engineering, Faculty of Engineering, University of Khartoum, Khartoum 11111, Sudan

8 CanmetENERGY Research Centre, Natural Resources Canada, 1 Haanel Drive, Ottawa, ON K1A 1M1, Canada

* Correspondence: ptsardari@tdtu.edu.vn (P.T.); wahiba.yaici@canada.ca (W.Y.); Tel.: +1-613-996-3734 (W.Y.)

Abstract: The melting heat transfer of nano-enhanced phase change materials was addressed in a thermal energy storage unit. A heated U-shape tube was placed in a cylindrical shell. The crosssection of the tube is a petal-shape, which can have different amplitudes and wave numbers. The shell is filled with capric acid with a fusion temperature of $32{ }^{\circ} \mathrm{C}$. The copper $(\mathrm{Cu}) /$ graphene oxide (GO) type nanoparticles were added to capric acid to improve its heat transfer properties. The enthalpy-porosity approach was used to model the phase change heat transfer in the presence of natural convection heat transfer effects. A novel mesh adaptation method was used to track the phase change melting front and produce high-quality mesh at the phase change region. The impacts of the volume fraction of nanoparticles, the amplitude and number of petals, the distance between tubes, and the angle of tube placements were investigated on the thermal energy rate and melting-time in the thermal energy storage unit. An average charging power can be raised by up to $45 \%$ by using petal shape tubes compared to a plain tube. The nanoadditives could improve the heat transfer by $7 \%$ for $\mathrm{Cu}$ and $11 \%$ for GO nanoparticles compared to the pure phase change material.

Keywords: quasi-petal heat transfer tube; thermal energy storage; nano-enhanced phase change materials

\section{Introduction}

Thermal energy storage systems have attracted numerous researchers due to their economic and environmental benefits. As the phase change materials can absorb and release latent heat during solidification and melting, they are widely used in thermal energy storage systems. The thermal energy storage adds a buffer to thermal systems to dampen their peak thermal loads or shift their thermal loads. The phase change materials are capable of storing a significant amount of latent energy in a small mass. For example, by using latent heat thermal energy storage, the solar heat can be stored during the daytime and later released during the night times [1]. Two major benefits of latent heat thermal energy storage are the high specific heat of phase change and low-temperature variation during thermal storage [2]. The latent thermal energy storage can also be used to cool 
photovoltaic panels [3] or load shift in buildings [4]. Various applications of phase change materials have been reviewed in the studies of Cui et al. [5], Kong et al. [6], and Abdolmaleki et al. [7].

The phase change materials (PCMs) are capable of storing a huge amount of thermal energy. However, one of the main drawbacks of PCMs is their low value of thermal conductivity. One way to enhance PCM's thermal conductivity is to produce nano-enhanced PCMs (NePCMs) by simply adding nanoparticles to the base PCM. Many innovations regarding NePCM [8-11] and thermal storage system design [12,13] are patented.

Considering NePCMs, Ho and Gao [14] tested the influence of adding nanoparticles of $\mathrm{Al}_{2} \mathrm{O}_{3}$ to $\mathrm{PCM}$ (paraffin) on melting heat transfer experimentally. Different nanoparticle mass fractions were studied under different Rayleigh and Stefan numbers. The results indicated that natural convection in the melting region is obviously degraded when the nanoparticle mass fraction increased. Dhaidan et al. [15] studied the melting of NePCM inside a square cavity by means of experimental work and numerical simulation. Their results indicated that dispersing $\mathrm{CuO}$ nanoparticles into PCM effectively increased both the thermal conductivity and temperature of NePCM, and most importantly, the charging time was reduced. Zeng et al. [16] experimentally researched the melting of NePCM in a cylindrical enclosure. NePCM was prepared by dispersing different loading of the carbon nanotubes (CNTs) in 1-dodecanol. They reported that the addition of CNTs led to a significant increase in the viscosity and thermal conductivity, and hence the melting rate was decelerated. Recently, Li et al. [17] used thermochromic liquid crystal to study the melting of NePCM in rectangular enclosures. Their findings were consistent with the literature, that melting rate was decelerated due to the significant increase of viscosity caused by using the NePCM.

Parsazadeh and Duan [18] numerically investigated the melting of NeCPM in a thermal storage unit. One of the main factors of the study was the influence of adding $\mathrm{CuO}$ particles to paraffin. The authors concluded that the addition of $\mathrm{CuO}$ nanoparticles to paraffin significantly improved heat transfer, however exceeding the critical nanoparticle concentration would result in an adverse effect. Hosseinizadeh et al. [19] explored the melting of NePCM inside a spherical container numerically. They employed RT27 and copper particles as nanoadditives. Their results confirmed that the melting rate of NePCM was enhanced when compared with PCM. Zhang et al. [20] conducted experimental work to investigate the characteristics of NePCM. They covered different nanoadditives, such as $\mathrm{Fe}_{2} \mathrm{O}_{3}$ and $\mathrm{Cu}$. They observed an increment in the thermal conductivity and a reduction in the thermal storage time.

The performance of the thermal energy system is significantly affected by the geometrical design and parameters. Some of the literature works investigated the influence of adding fins to enhance the conductive heat transfer inside the system. For example, Ji et al. [21] attempted to improve PCM's melting rate by introducing fins with a tilting angle. They reported that the fin with a downward angle of $-15^{\circ}$ accelerated the melting of PCM and resulted in $23.8 \%$ melting time-saving. Jinlong et al. [22] presented a numerical study on thermal optimization of a tree-shaped metal structure to enhance heat transfer in the PCM cavity. Their results indicated that the proposed optimized structure enhanced the melting fraction of PCM.

Mostafavi et al. [23] analytically modeled PCM melting in a cylinder containing transverse and longitudinal fins. It was reported that thin fins resulted in significant enhancement of heat transfer; however, further increment in fin size led to adverse effects. Pourakabar et al. [24] numerically investigated the influence of shell geometry (circular and elliptical cylinders) and tube arrangement on the phase change rate of PCM inside the cylinder. In total, nine different study cases were considered. The maximum melting rate was achieved by a circular cylinder with two tubes vertically aligned.

Some recent researchers used a combination of fins and NePCMs to improve heat transfer further and accelerate thermal energy storage and release process. Sheikholeslami [25] presented a numerical simulation of NePCM solidification in a cavity containing metallic 
fins. Nguyen-Thoi et al. [26] analyzed the solidification of NePCM in a thermal storage system with Y-shaped fins. Sheikholeslami et al. [27] numerically simulated melting of NePCM in a finned cavity. The results of all these studies showed that using longer fins reduced both the solidification time and total energy. Mahdi et al. [28] numerically compared the thermal performance of a triplex tube when loaded with NePCM to the same system loaded with PCM and containing inner fins. Considering charging and discharging the system, it was clearly observed that incorporating inner fins is much better than the dispersion of nanoparticles in base PCM.

Another possible effective solution to enhance the solidification and melting rates of the thermal storage system is to increase the surface area of the inner tube. Zhang et al. [29] investigated the discharging of NePCM in a thermal storage system with a triplex tube with different values of sinusoidal amplitudes. They concluded that using higher value sinusoidal amplitude resulted in reducing the discharge time by $7.58 \%$. Alizadeh et al. [30] numerically explored the influence of Koch snowflake fractal-shaped tube on the thermal performance of NePCM thermal storage systems. The study considered four different cross-sectional shapes, where Koch-snowflake-iteration ranges from zero to 3 . Their results indicated that using higher values of Koch-snowflake-iteration increased the penetration depth, which consequentially accelerated the solidification process.

Sheikholeslami et al. [31] numerically studied heat transfer of NePCM inside sinusoidal enclosure contacting V-shaped fins. One of the main studied parameters was the effect of the V-shaped angle on the solidification rate. The results indicated that the discharging rate was augmented for high values of fin angle. Li et al. [32] attempted to accelerate the solidification of NePCM in a circular cylindrical thermal energy storage unit by optimizing the shape of the wall of the inner tube. The study considered different shapes of inner tubes that have a different number of undulations (ranges from 3 to 5 ) and different amplitude values (ranges from 0.1 to 0.5 ). The research outcome indicated that decreasing the amplitude resulted in increasing the solidification time, whereas increasing the number of petals has a favorable effect. In another investigation, Sheikholeslami [33] numerically investigated the effect of inner tube geometry on NePCM solidification in an elliptic cylindrical thermal storage system. The main geometrical parameters of the inner tube were the number of undulations $(3,4$, and 5$)$ and the amplitude $(0.1 .0 .3$, and 0.5$)$. It was observed that solid fraction was directly proportional to the number of undulations, while total energy profiles were inversely proportional to the number of undulations.

Indeed, many researchers are preparing various types of novel NePCMs with improved thermophysical properties with the aim of better thermal energy storage and heat transfer. Tariq et al. [34] and Nižetić [1] have reviewed some of the NePCM materials and applications. However, the NePCMs add mixed impacts on a thermal energy storage design. For example, the presence of nanoparticles improves the thermal conductivity of PCM, which consequently enhances the conduction and convection heat transfer. This is while the presence of nanoparticles could also increase the dynamic viscosity, which weakens the natural convection flows in a molten PCM. Moreover, the latent heat of phase change, heat capacity, and other properties could be changed in the presence of the nanoadditives. These aspects impose complex effects on thermal performance of a thermal energy storage unit. Thus, these nanomaterials should be applied in thermal energy storage systems, and then their benefit can be judged.

The literature studies confirm that the undulating shape of the heat transfer tube could increase the heat transfer surface and the natural convection flows. Thus, the wavy enclosures and petal tubes could be promising candidates for the improvement of heat transfer and enhance the rate of energy storage in thermal energy storage units. The present study, for the first time, aims to investigate the impact of using petal heat transfer tubes and $\mathrm{NePCMs}$ on the heat transfer performance and energy storage rate of thermal energy storage units. The number and amplitude of the undulations and location of tubes are investigated. 


\section{Methodology}

\subsection{Physical Model}

Figure 1 depicts the schematic configuration of a heat exchanger energy storage system. As the schematic view in Figure 1a illustrates, the system includes a shell and a U-shaped tube containing the hot heat transfer fluid (HTF). As can be seen in Figure 1b, the crosssection of the tube is a quasi-petal and the line passing the centers of the heat transfer tube with respect to the $x$-axis is $\eta$.

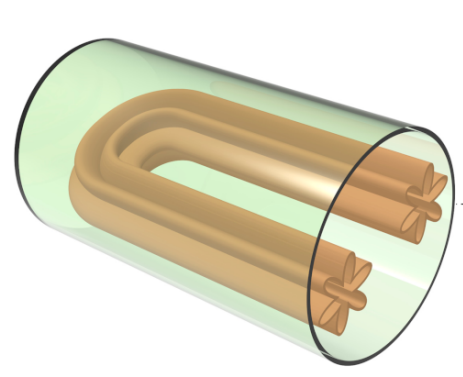

(a)

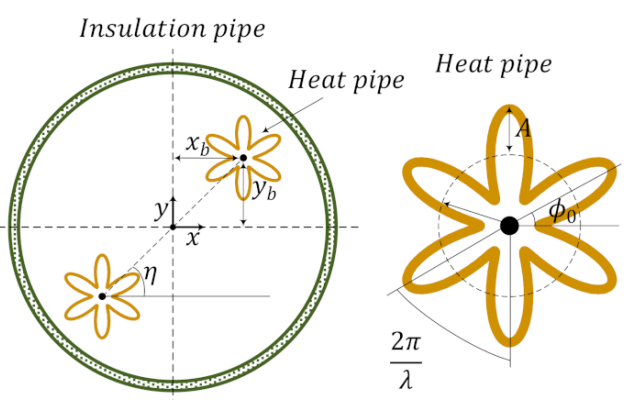

(b) (c)

Figure 1. The configuration of the problem physics: (a) a 3D view of the energy storage unit with petal heat transfer fluid (HTF); (b) a 2D cross-section of the unit; (c) geometrical details of a petal tube.

Since the tube material is thermally high conductive, its thickness is negligible compared to the radius. The void space between the U-shaped tube and the shell is occupied with the NePCM in which the host PCM is capric acid with a nominal melting point of $T_{m}=32{ }^{\circ} \mathrm{C}$. The shell of the heat exchanger storage system is well insulated, while initially $(t=0)$, the temperatures of the NePCM and quasi-petal heat transfer tube are $T_{c}=22{ }^{\circ} \mathrm{C}$. At $t=24 \mathrm{~s}$, the temperature of the heat transfer tube linearly rises so that it reaches $T_{h}=42{ }^{\circ} \mathrm{C}$ at $t=25 \mathrm{~s}$. It is worth noting that the temperature of the heat transfer tube is considered to be constant at $T_{h}$ during the charging process.

The dispersed nano-additives can be copper $(\mathrm{Cu})$ or graphene oxide $(\mathrm{GO})$ ones. The thermophysical properties of the components of the NePCM are listed in Table 1.

Table 1. Thermophysical properties of the paraffin wax and the nano-additives $[35,36]$.

\begin{tabular}{cccc}
\hline Properties & Cu & GO & Capric Acid \\
\hline Density $\left(\mathrm{kg} \mathrm{m}^{-3}\right)$ & 8933 & 1800 & Solid: 1018 \\
Latent heat $\left(\mathrm{kJ} \mathrm{kg}^{-1}\right)$ & $\mathrm{NA}$ & $\mathrm{NA}$ & Liquid: 888 \\
Thermal expansion coefficient $\left(\mathrm{K}^{-1}\right)$ & $1.67 \times 10^{-5}$ & $28.4 \times 10^{-5}$ & $1 \times 10^{-3}$ \\
Fusion temperature $\left({ }^{\circ} \mathrm{C}\right)$ & $\mathrm{NA}$ & $\mathrm{NA}$ & 32 \\
Thermal conductivity $\left(\mathrm{Wm}^{-1} \mathrm{~K}^{-1}\right)$ & 401 & 5000 & Solid: 0.372 \\
Specific heat $\left(\mathrm{kJ} \mathrm{kg}^{-1} \mathrm{~K}^{-1}\right)$ & 0.385 & 0.717 & Liquid: 0.153 \\
Solid: 1.9 \\
Kinematic viscosity $\left(\mathrm{m}^{2} \mathrm{~s}^{-1}\right)$ & $\mathrm{NA}$ & $\mathrm{NA}$ & Liquid: 2.4 \\
\hline
\end{tabular}

NA: Not applicable.

Herein, the density variations of the NePCM during phase change are considered to be zero, and the reference densities are selected to simulate the process. The Boussinesq approximation is valid to model the buoyancy-driven convection of the melted NePCM. The radius of the sinusoidal cross-section of the quasi-petal heat transfer tube is defined by using the following relation:

$$
r=r_{b}+A \times \sin (\Lambda s),
$$

As shown in Figure $1 c, r_{b}$ and $A$ are the radius of the base circle and the sinusoidal amplitude of the quasi-petal heat transfer tube. $\Lambda$ is the number of petals and $s$ is the angle 
of the quasi-petal heat transfer tube. The cross-section surface area of the quasi-petal tube $\left(A_{p}\right)$ is calculated as follows:

$$
A_{p}=\int_{0}^{2 \pi} \frac{1}{2} r^{2} d \phi=\frac{\pi}{2}\left(A^{2}+2 r_{b}^{2}\right)-\frac{A^{2}}{8 \Lambda} \sin (4 \pi \Lambda)+\frac{A r_{b}}{\Lambda}(\cos (2 \pi \Lambda)-1),
$$

When $\Lambda \in N$ then:

$$
A_{p}=\frac{\pi}{2}\left(A^{2}+2 r_{b}^{2}\right)
$$

which is independent of $\Lambda$. It worth noting that $A_{p}$ is considered to be constant so that $A_{p}=\pi r_{s}^{2} / 20$. The radius of the shell, i.e., $r_{s}$, is $20 \mathrm{~mm}$, and $r_{b}$, i.e., the radius of the base circle, is defined by using Equation (3).

\subsection{Governing Equations}

The governing equations for conservation of mass, flow, and energy in the heat exchanger can be written as [37-39]:

$$
\begin{gathered}
\frac{\partial u}{\partial x}+\frac{\partial v}{\partial y}=0 \\
\rho_{N e P C M, l}\left(\frac{\partial u}{\partial t}+u \frac{\partial u}{\partial x}+v \frac{\partial u}{\partial y}\right)=-\frac{\partial p}{\partial x}+\mu_{N e P C M}\left(\frac{\partial^{2} u}{\partial x^{2}}+\frac{\partial^{2} u}{\partial y^{2}}\right)-f(T) u \\
\rho_{N e P C M, l}\left(\frac{\partial v}{\partial t}+u \frac{\partial v}{\partial x}+v \frac{\partial v}{\partial y}\right)=-\frac{\partial p}{\partial y}+\mu_{N e P C M}\left(\frac{\partial^{2} v}{\partial x^{2}}+\frac{\partial^{2} v}{\partial y^{2}}\right)-f(T) v+(\rho \beta)_{N e P C M, l} g\left(T-T_{m}\right) \\
\left(\rho C_{p}\right)_{N e P C M}\left(\frac{\partial T}{\partial t}+u \frac{\partial T}{\partial x}+v \frac{\partial T}{\partial y}\right)=\frac{\partial}{\partial x}\left(\kappa_{N e P C M} \frac{\partial T}{\partial x}\right)+\frac{\partial}{\partial y}\left(\kappa_{N e P C M} \frac{\partial T}{\partial y}\right) \\
-\left(1-\omega_{v f}\right) \rho_{P C M, l} h_{s f, P C M} \frac{\partial x(T)}{\partial t}
\end{gathered}
$$

where Equation (4) is the conservation of mass for an incompressible liquid. Equations (5) and (6) are the momentum equations in the $x$-direction $(u)$ and y-direction $(v)$, respectively. In the $y$-momentum equation, the buoyancy forces are modeled using the Boussinesq approximation by considering the liquid's volume expansion coefficient ( $\beta$ ). Equation (7) denotes the conservation of energy, including the phase change latent heat and temperature field $(T)$. The phase change is modeled using a temperature-dependent latent heat term, $\chi(T)$. The symbols $\kappa, h_{s f}, C_{p}, \rho, \mu$, and $\omega_{v f}$ represent the thermal conductivity, latent heat, heat capacity, density, dynamic viscosity, and volume fraction of nanoparticles. The subscripts, NePCM, PCM, and 1 show the nano-enhanced phase change material, the base phase change material, and the molten state. Here, $f(T)$, as a function of the liquid fraction of the NePCM, i.e., $\chi$, is the momentum sink term, is defined by using the Kozeny-Carman model.

$$
f(T)=\varepsilon \frac{(1-\chi(T))^{2}}{\chi(T)^{3}+\xi}
$$

It is evident this term is zero and infinity for the completely melted and solid zones. $\varepsilon$, the mushy zone constant, shows the approximate magnitude of damping in the momentum equations. This constant is set to $10^{5}$. Likewise, $\xi$ is set to a very low value to prevent division by zero at the melted zone. The liquid fraction of the NePCM, which is defined based on the temperature, is:

$$
\chi(T)=\left\{\begin{array}{lc}
0 & T<T_{m}-\frac{\delta T}{2} \\
\frac{T-T_{m}}{\delta T}+\frac{1}{2} & T_{m}-\frac{\delta T}{2}<T<T_{m}+\frac{\delta T}{2}, \\
1 & T>T_{m}+\frac{\delta T}{2}
\end{array}\right.
$$


which $T_{m}$ is the melting temperature, and $\delta T$ is the melting temperature window. The density of NePCM is:

$$
\begin{gathered}
\rho_{N e P C M}=\left(1-\omega_{v f}\right) \rho_{P C M}+\omega_{v f} \rho_{n a}, \\
\rho_{P C M}(T)=\rho_{P C M, l} \chi(T)+(1-\chi(T)) \rho_{P C M, s}
\end{gathered}
$$

The dynamic viscosity of the composite can be estimated by Brinkman's model as:

$$
\mu_{N e P C M}=\frac{\mu_{P C M}}{\left(1-\omega_{v f}\right)^{2.5}}
$$

The thermal-volume expansion coefficient of the composite is:

$$
(\rho \beta)_{N e P C M, l}=\left[\left(1-\omega_{v f}\right)(\rho \beta)_{P C M, l}+\omega_{v f}(\rho \beta)_{n a}\right],
$$

Furthermore, the effective thermal conductivity of the composite is estimated as the following:

$$
\kappa_{N e P C M}(T)=\kappa_{N e P C M, l} \chi(T)+(1-\chi(T)) \kappa_{N e P C M, s}
$$

in which [40]

$$
\frac{\kappa_{N e P C M, i}}{\kappa_{P C M, i}}=\frac{\left(\kappa_{n a}+2 \kappa_{P C M, i}\right)-2 \omega_{v f}\left(\kappa_{P C M, i}-\kappa_{n a}\right)}{\left(\kappa_{n a}+2 \kappa_{P C M, i}\right)+\omega_{v f}\left(\kappa_{P C M, i}-\kappa_{n a}\right)}
$$

$i=l, s$ in the above equation denotes the liquid and solid phase of the PCM, respectively. Additionally, the effective heat capacity of the NePCM was computed by:

$$
\begin{gathered}
(\rho C)_{p, N e P C M}=\left[\left(1-\omega_{v f}\right)\left(\rho C_{p}\right)_{P C M}+\omega_{v f}\left(\rho C_{p}\right)_{n a}\right], \\
\left(\rho C_{p}\right)_{P C M}(T)=\left(\rho C_{p}\right)_{P C M, l} \chi(T)+(1-\chi(T))\left(\rho C_{p}\right)_{P C M, s^{\prime}}
\end{gathered}
$$

The energy stored in the composite is calculated as the following:

$$
E S=\int_{A} \int_{T_{i n}}^{T_{s}}\left(\rho C_{p}\right)_{N e P C M, s} d T d A+\int_{A}\left(\rho h_{s f}\right)_{N e P C M} d A+\int_{A} \int_{T_{l}}^{T}\left(\rho C_{p}\right)_{N e P C M, l} d T d A .
$$

\section{Numerical Method and Model Verification}

\subsection{Numerical Approach}

The parameters can be studied in this work are $r_{d}, A, \Lambda, \omega_{v f}$, and $\eta$ with the following ranges: $0.4 r_{s}, \leq r_{d} \leq 0.6 r_{s}, 0 \leq A \leq 0.15 r_{s}, 2 \leq \Lambda \leq 8,0.0 \% \leq \omega_{v f} \leq 8 \%$, and $0 \leq \eta \leq \pi / 2$. Moreover $\phi_{0}$, i.e., the angle of the first petal with respect to the horizontal direction can be varied based on the number of petals. In this simulation, we calculate all the data for $75 \%$ of the melting volume fraction (MVF). The models were computed for $2000 \mathrm{~s}$ of phase change heat transfer. It should be considered that total energy stored is the summation of the sensible and latent energies. Therefore, the average charging power was computed as the total energy over melting time related when MVF reaches $75 \%$ of the total melting.

In order to model the melting procedure, the source terms of momentum and energy conservation equations depended on the formulas of NePCM mentioned above are used. $f(T)$ source term is applied to control the velocity field. Three different areas can be considered for the domain study, solid, liquid, and the mushy zone. The mushy zone helps to separate the two other areas. These three areas are separated by the melting temperature window, $\delta T$, and fusion temperature. There is a high-velocity gradient area within the porous part of the mushy zone, including solid and liquid materials. The heat-source of the mushy zone, $\left(\rho h_{s f}\right)_{N e P C M}(\partial \chi(T) / \partial t)$, that is the energy source term, contributes to a high-gradient temperature zone and also controls the melting area. To capture the mushy 
zone from the high-gradient parameters viewpoint completely, the mesh adoption process as a progressive technique inside the mushy zone is utilized to achieve a quality grid.

Galerkin finite element method [41,42] by using user-defined codes is applied to solve the nonlinear differential equations written above. In this method, a weak form of equations and corresponding initial and boundary conditions are made and are solved afterward. The dependent variables of the study $u, v, p$, and $T$ are expanded by a shape set, $\left\{b_{v}\right\}_{v=1}^{I}$.

$$
(T, p, v, u) \approx \sum_{v=1}^{I}\left(T_{v}, p_{v}, v_{v}, u_{v}\right) b_{v}(x, y)
$$

Based on Galerkin finite element method, the residual functions, expressed below, are:

$$
\begin{gathered}
Q_{t}^{1} \approx \sum_{v=1}^{I} v_{v} \int \frac{\partial b_{v}}{\partial y} b_{t} d x d y+\sum_{v=1}^{I} u_{v} \int \frac{\partial b_{v}}{\partial x} b_{t} d x d y, \\
Q_{t}^{2} \approx \rho_{N e P C M, l} \sum_{v=1}^{I} u_{v} \int \frac{\partial b_{v}}{\partial t} b_{t} d x d y+\rho_{N e P C M, l} \sum_{v=1}^{I} u_{v} \int\left[\left(\sum_{v=1}^{M} u_{v} b_{v}\right) \frac{\partial b_{v}}{\partial x}+\left(\sum_{z=1}^{I} v_{v} b_{v}\right) \frac{\partial b_{v}}{\partial y}\right] b_{t} d x d y \\
+\sum_{v=1}^{I} \int\left(-\sum_{v=1}^{I} p_{v} b_{v}\right) \frac{\partial b_{v}}{\partial x} b_{t} d x d y+\mu_{N e P C M} \sum_{v=1}^{I} u_{v} \int \frac{\partial b_{v}}{\partial x} \frac{\partial b_{t}}{\partial x} d x d y \\
+\mu_{N e P C M} \sum_{v=1}^{I} u_{v} \int\left[\frac{\partial b_{v}}{\partial y} \frac{\partial b_{t}}{\partial y}\right] d x d y-\mu_{N e P C M} \int\left(\sum_{v=1}^{I} u_{v} b_{v}\right) b_{t} d x d y-f(T) \int\left(\sum_{v=1}^{I} u_{v} b_{v}\right) b_{t} d x d y \\
Q_{t}^{3} \approx \rho_{N e P C M, l} \sum_{v=1}^{I} v_{v} \int \frac{\partial b_{v}}{\partial t} b_{t} d x d y+\rho_{N e P C M, l} \sum_{v=1}^{I} v_{v} \int\left[\left(\sum_{v=1}^{M} u_{v} b_{v}\right) \frac{\partial b_{v}}{\partial x}+\left(\sum_{z=1}^{M} v_{v} b_{v}\right) \frac{\partial b_{v}}{\partial y}\right] b_{t} d x d y \\
+\sum_{v=1}^{I} \int\left(-\sum_{v=1}^{I} p_{v} b_{v}\right) \frac{\partial b_{v}}{\partial y} b_{t} d x d y+\mu_{N e P C M} \sum_{v=1}^{I} v_{v} \int \frac{\partial b_{v}}{\partial x} \frac{\partial b_{t}}{\partial x} d x d y \\
+\mu_{N e P C M} \sum_{v=1}^{I} v_{v} \int\left[\frac{\partial b_{v}}{\partial y} \frac{\partial b_{t}}{\partial y}\right] d x d y-\mu_{N e P C M} \int\left(\sum_{v=1}^{I} v_{v} b_{v}\right) b_{t} d x d y \\
-f(T) \int\left(\sum_{v=1}^{M} v_{v} b_{v}\right) b_{t} d x d y+(\rho \beta)_{N e P C M, l} g\left(\int\left(\sum_{v=1}^{I} T_{v} b_{v}\right) b_{t} d x d y-T_{m}\right) \\
Q_{t}^{4} \approx\left(\rho C_{p}\right)_{N e P C M} \sum_{v=1}^{I} T_{v} \int \frac{\partial b_{v}}{\partial t} b_{t} d x d y \\
+\left(\rho C_{p}\right)_{N e P C M} \sum_{v=1}^{I} T_{v} \int\left[\left(\sum_{v=1}^{I} u_{v} b_{v}\right) \frac{\partial b_{v}}{\partial x}+\left(\sum_{v=1}^{I} v_{v} b_{v}\right) \frac{\partial b_{v}}{\partial y}\right] b_{t} d x d y \\
+k_{N e P C M} \sum_{v=1}^{I} T_{v} \int\left[\frac{\partial b_{v}}{\partial x} \frac{\partial b_{t}}{\partial x}+\frac{\partial b_{v}}{\partial y} \frac{\partial b_{t}}{\partial y}\right] d x d y-(\rho h)_{N e P C M} \sum_{v=1}^{I} \frac{\partial x(T)}{\partial T} \int \frac{\partial b_{b}}{\partial t} b_{t} d x d y
\end{gathered}
$$

where

$$
\frac{\partial \chi(T)}{\partial T}= \begin{cases}0 & T \leq T_{m}-\frac{1}{2} \delta T \\ \frac{1}{\delta T} & T_{m}-\frac{1}{2} \delta T<T<T_{m}+\frac{1}{2} \delta T, \\ 0 & T \geq T_{m}+\frac{1}{2} \delta T\end{cases}
$$

The second-order Gaussian-quadrature approach is employed to integrate residual formulas written above. In the above equations, $Q$ is the residual equations corresponding to the governing equations. The subscript $t$ denotes the time, and the superscript numbers indicate the equation numbers. Integrating each of the residual equations over the domain of solution produces an algebraic equation for each of the domain elements. Then, the set of algebraic equations should be solved numerically to provide the numeric values of the dependent variables. More information around the Galerkin finite element technique is explained in Refs. [41,42]. A phase-field term, $\chi_{0}$, is a limit for the mesh adoption and $\chi_{0}$, shows the space-domain for grid adoption. In comparison to the temperature gradient $\delta T$, the phase change phenomenon happens at a thicker gradient, $3 \delta \mathrm{T} / 2$. According to this thicker temperature field, known as fusion bond, a smoother transient of the grid around 
the interface area is achieved due to the wider domain around the melting or solidification interface. The phase-field term, i.e., $\chi_{0}(T)$, is as the following:

$$
\chi_{0}(T)= \begin{cases}0 & T \leq T_{m}-\frac{3}{2} \delta T \\ 1 & T_{m}-\frac{3}{2} \delta T<T<T_{m}+\frac{3}{2} \delta T, \\ 0 & T \geq T_{m}+\frac{3}{2} \delta T\end{cases}
$$

Moreover, by locating the interface inside the grid adoption domain, the elements of mesh will be sufficient. In this regard, the bigger grid adoption zone around the interface leads to a lower adoption procedure. The time step is controlled by employing an automatic approach named backward differentiation formula (BDF) [43]. The residual error $\mathrm{O}\left(10^{-6}\right)$ and a Newtonian damping factor of 0.8 in parallel direct solver (PARDISO) [44-46] are chosen for solving the residual relations of Equations (20)-(23), iteratively.

\subsection{Grid-Independency Test}

To achieve accurate results, four various meshes of different element numbers, shown in Table 2, are chosen to perform the grid-independency test. The variable of comparison among the different grid cases is the melted volume fraction for $\eta=\pi / 4, \omega_{C u}=0.04$, $\Lambda=8, A=0.15, r_{d}=0.6 r_{s}$.

Table 2. Specifics of the utilized meshes for the grid dependency test.

\begin{tabular}{ccccc}
\hline Grid Case & $\mathbf{1}$ & $\mathbf{2}$ & $\mathbf{3}$ & $\mathbf{4}$ \\
\hline elements & 7926 & 12,385 & 17,761 & 23,854 \\
computing time & 118 & 184 & 215 & 247 \\
\hline
\end{tabular}

* The second column was adopted for computations.

As can be seen from Figure 2, there is not a dramatic difference between the results of the studied meshes; however, the three latest are most similar. Due to experiencing lower cost and number of numerical calculations, case 2 was chosen for studies. In this case, there were 12,385 elements. According to Figure $3 a-c$, the mesh deformation and the adaptive refinement at $t=0,1000$, and 1500 can be seen. A good transient is evident in figures in which the orange color shows the liquid region and the blue one represents the solid region.

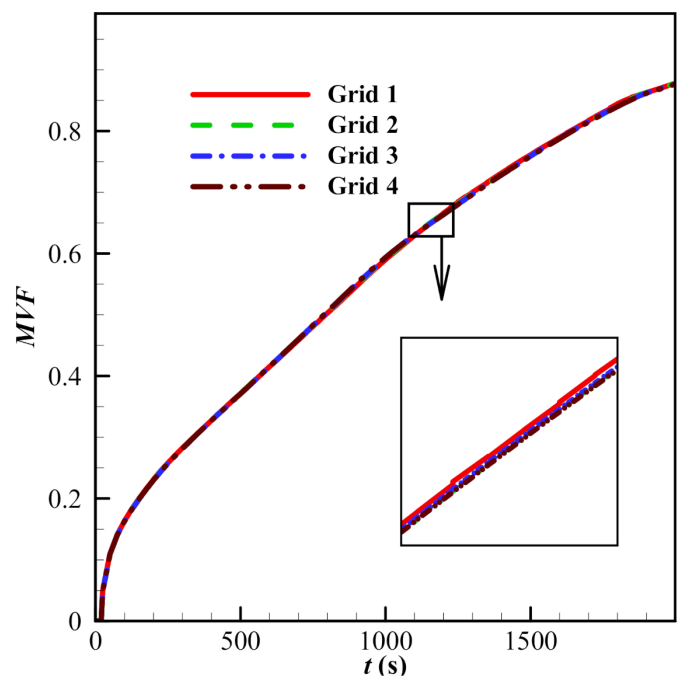

Figure 2. Dependency of melting volume fraction of nano-enhanced phase change material (NePCM) on the mesh size for $\omega_{C u}=0.04, \Lambda=8, A=0.15, r_{d}=0.6 r_{s}$, and $\eta=\pi / 4$. 


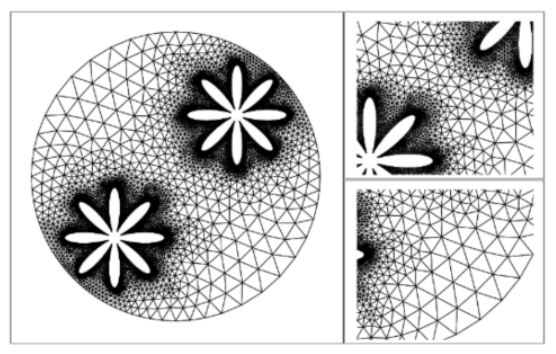

(a)

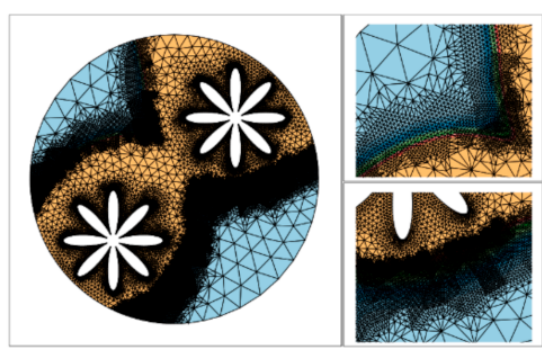

(b)

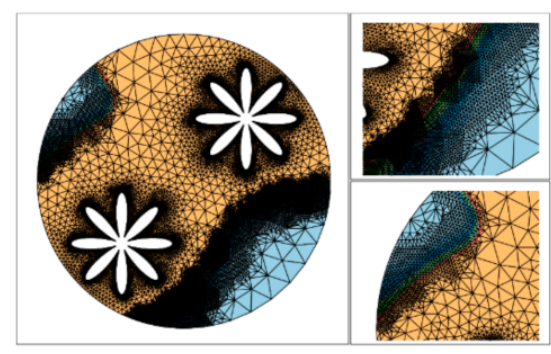

(c)

Figure 3. The adopted meshes and the mesh adaptations, corresponding to the grid case 2 when $t$ is equal to (a): $0 \mathrm{~s},(\mathbf{b}): 1000 \mathrm{~s}$, and (c): $1500 \mathrm{~s}$.

\subsection{Model Verification}

It is necessary to examine the accuracy of the results of this study by comparing them with the results of related literature. This includes both numerical and experimental investigations. The research of Kumar et al. [47] done experimentally is the first case of validation. The vertical walls of their study were imposed on the constant heat flux, and horizontal walls were adiabatic. The present study's results and those of [47] around the melting front at $R a=1.4 \times 10^{7}, \operatorname{Pr}=0.0236$, and Ste $=0.4$ are demonstrated in Figure 4a. Here, $R a=\rho g \beta\left(T_{h}-T_{f}\right) H^{3} / \alpha \mu$, Ste $=C_{P}\left(T_{h}-T_{f}\right) / h_{s f}, P r=\mu / \rho \alpha$, and $F o=t \alpha / H^{2}$ where $H$ is the characteristic size, and $\alpha=k /\left(\rho C_{p}\right)$. A good agreement is seen between the graphs of the melting front of both studies. Afterward, the study of Ref. [48] is another case of validation. The melting front of a base PCM (without any particle) and its melting process inside a square cavity were the cases of their superior investigations. Two vertical walls with different constant temperatures $\left(T_{h}>T_{c}\right)$, and two adiabatic horizontal walls were their main boundary conditions. The case of validation was selected for the non-dimensional parameters of Fo. Ste $=0.002$ and 0.01 when $R a=1.25 \times 10^{5}$ and $P r=50$. Moreover, as depicted in Figure $4 \mathrm{~b}$, the melting fronts obtained by the current model are compared to the numerical results reported in $[49,50]$. According to Figure $4 b$, acceptable agreements are seen between the results of the current study and [49-51].

Li et al. [17] examined the melting of graphene nanoparticles-1-tetradecanol NePCM in a rectangular enclosure of height $2.5 \mathrm{~cm}$ and width $2.0 \mathrm{~cm}$. The enclosure walls were insulated except a vertical wall which was heated with an isothermal temperature of $47^{\circ} \mathrm{C}$. The initial NePCM temperature and the melting temperature were $36^{\circ} \mathrm{C}$ and $37^{\circ} \mathrm{C}$, respectively. The melting process was investigated for $1 \% \mathrm{wt}$. Figure $4 \mathrm{c}$ compares the variation of MVF during the melting process obtained numerically in the present study and those measured in [17], which shows a good agreement. 


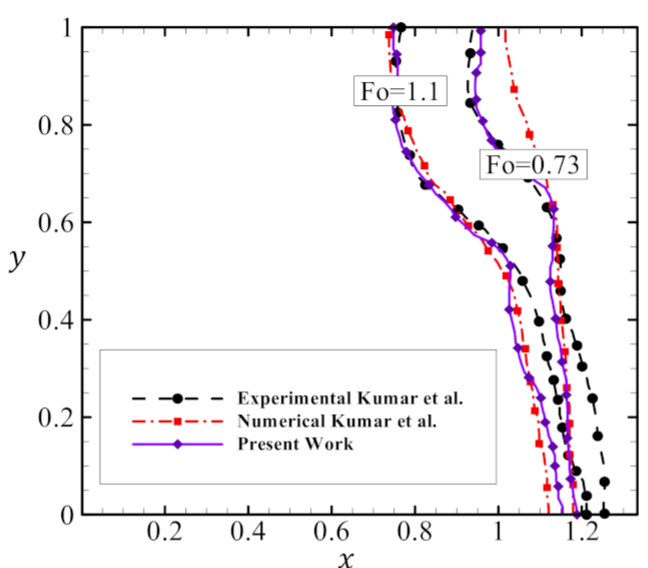

(a)

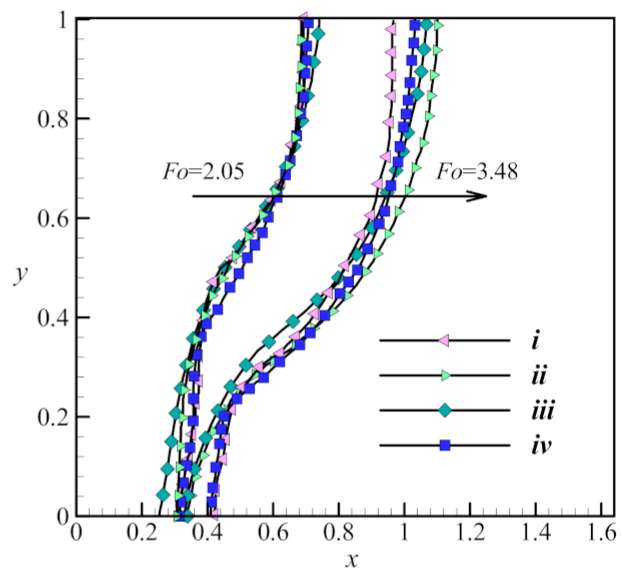

(b)

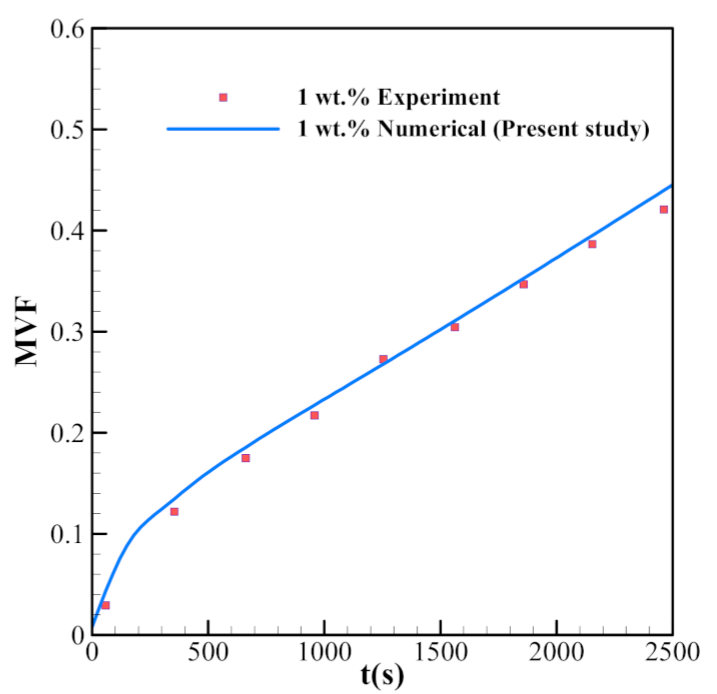

(c)

Figure 4. Comparison of melting domains: (a) the investigation of Kumar et al. [47] and the present study; (b) and literature works of [48]; i: Kashani et al. [51], ii: Gau and Viskanta [49] (experiment); iii: Brent et al. [50], and iv: present work; (c) NePCM melting of 1-tetradecanol containing 1\% wt. graphene nanoplatelets a comparison of melting volume fraction (MVF) measured in [17] and computed in the present study.

As the last case of validation, the investigation of Kuehn and Goldstein [52] performed experimentally is chosen to check the accuracy of the natural convection heat transfer characteristics. The domain of their study included the area between two horizontal cylinders. According to Figure 5, similar behavior is seen in the case of isotherm contours of two studies when $\operatorname{Pr}=6.19$ and $\operatorname{Ra}=2.33 \times 10^{5}$ demonstrating desirable agreement. 


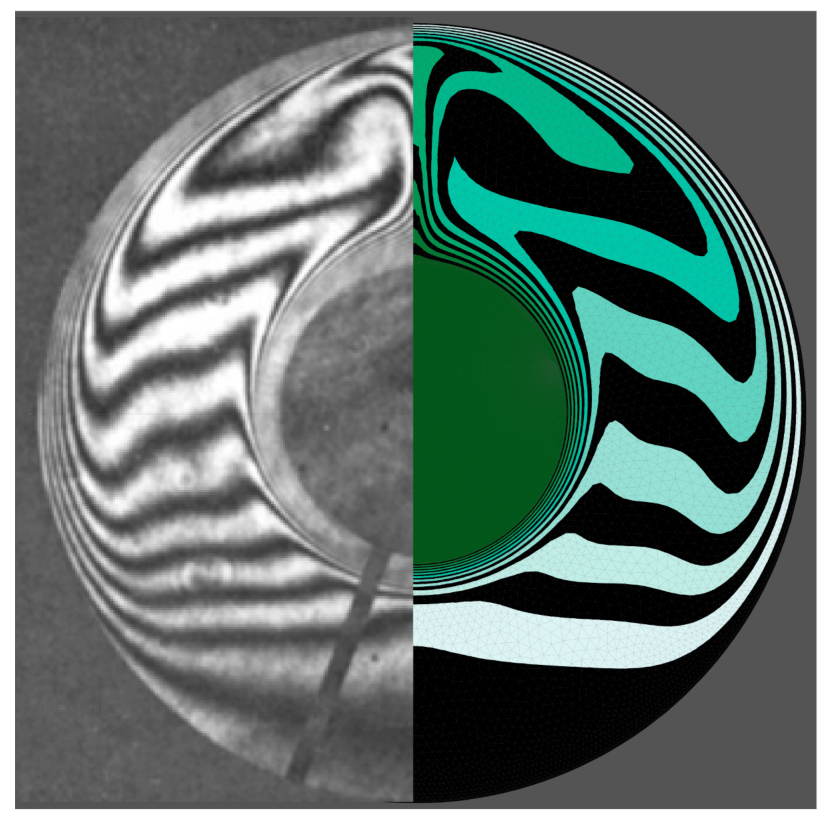

Figure 5. Isotherms of this work (left) and Ref. [52] (right).

\section{Results and Discussion}

The isotherms and the streamlines in the cavity are depicted in Figure 6 for different values of the number of petals $\Lambda$. The fusion temperature of the PCM here is $T_{m}=305 \mathrm{~K}$. Noting that the PCM remains in the solid-state in the zones where the temperature is lower than $T_{m}$, while it melts once the temperature exceeds $T_{m}$. It can be seen in Figure 6 that at $t=750 \mathrm{~s}$, the PCM is heated in the regions surrounding the petals of the inner pipe. The effect of the petal shape of the inner pipe is more apparent when the value of $\Lambda$ is above 2 , as it can be seen that the region of the melted PCM around the tube petals is greater compared to a circular tube $(\Lambda=0)$. In fact, as the number of the petals increases, the surface contact between the heated tube and the PCM increases and enhances heat transfer, which results in a greater melting zone.

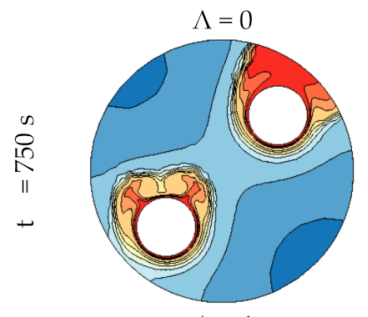

$\Lambda=4$

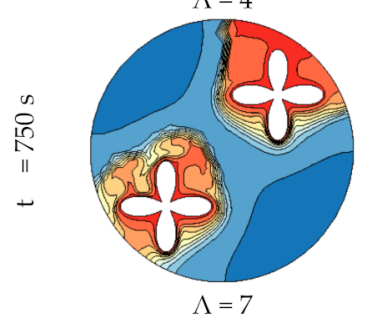

Figure 6. Cont.
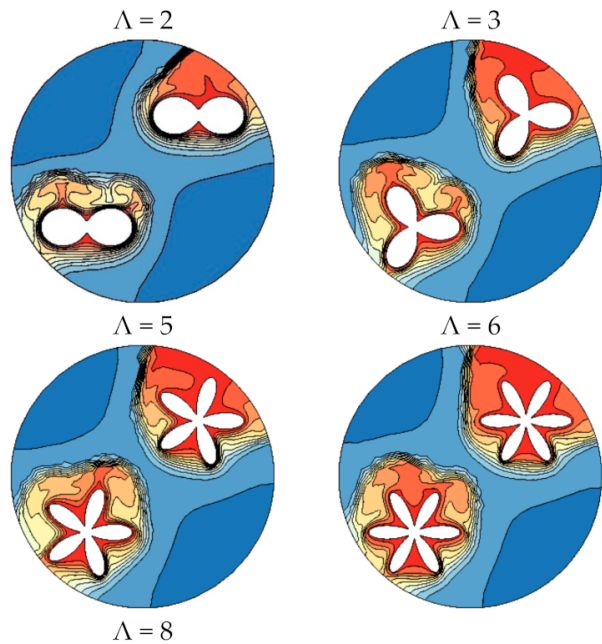


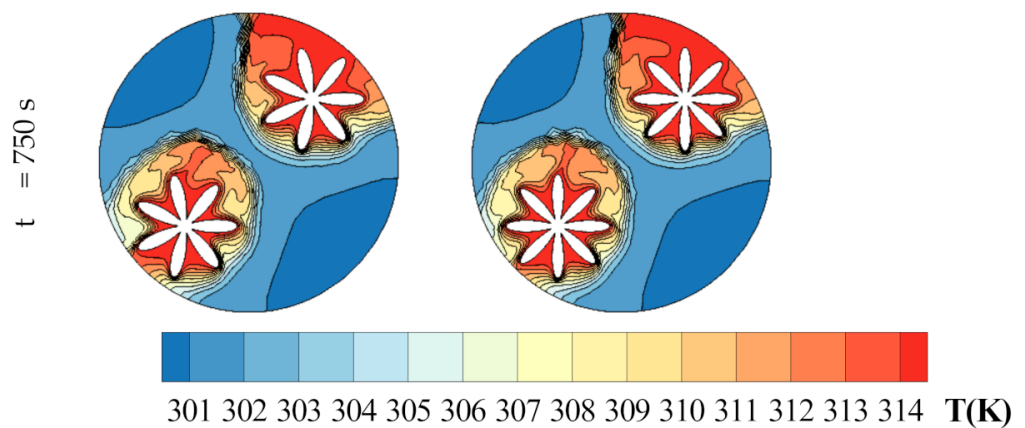

Figure 6. Effect of $\Lambda$ on the isotherms at $t=750 \mathrm{~s}$ and when $r_{d}=0.6 r_{s}, \omega_{C u}=0.04, \eta=\pi / 4$, $A=0.15 r_{s}$.

Figure 7 depicts the variations of the melted volume fraction MVF and the total stored energy $E S$ as functions of time. The trend of variation is the same for all the values of $\Lambda$, and a rise in both MVF and ES can be observed when $\Lambda$ is increased. The case of an inner circular tube $(\Lambda=0)$ represents the minimum melted volume and stored energy, which is due to the reduced heat transfer in that case compared to a petal cross-section.

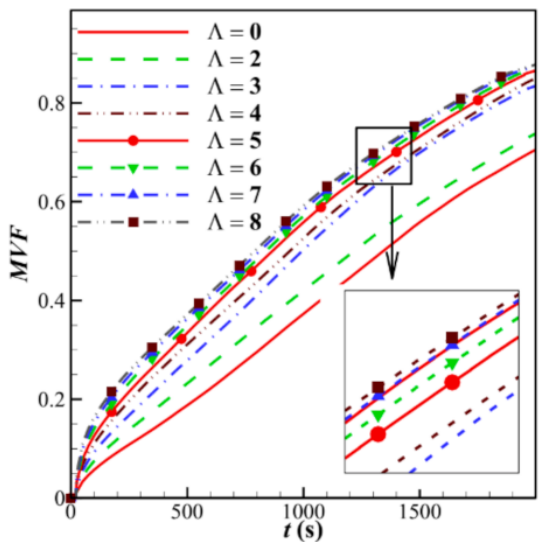

(a)

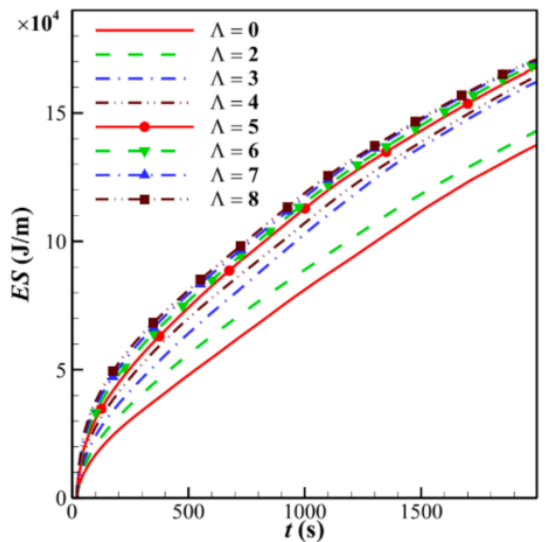

(b)

Figure 7. The variation of melting volume fraction (MVF) (a) and ES $(\mathrm{J} / \mathrm{m})(\mathbf{b})$ based on the change in $\Lambda$ when $r_{d}=0.6 r_{s}, \omega_{C u}=0.04, \eta=\pi / 4$, and $A=0.15 r_{s}$.

The variation of the average charging power (ACP) as a function of the number of petals $\Lambda$ is plotted in Figure 8 . The ACP is the ratio of the stored energy to the time required for full melting. It is, thus, a combination of the effects of MVF and ES. As MVF increases with $\Lambda$, the full melting time decreases. For this reason, it is clear that ACP increases with $\Lambda$ due to the higher values of ES in that case, as discussed in Figure 7. Moreover, the increase of ACP is for both latent and sensible heat, indicating that raising the number of petals enhances heat transfer and PCM melting. A 45\% increase in the total charging power can be obtained when using an inner tube with 8 petals compared to a circular tube.

The effect of the petal amplitude A on the time evolution of the isotherms and the streamlines is illustrated in Figure 9. At $t=500 \mathrm{~s}$, the PCM heating is limited to the zone surrounding the inner tube. As time goes, the zone of PCM melting increases in size, and it can be seen that this zone is greater when $A$ is raised. At $t=1500 \mathrm{~s}$, around half of the cavity remains filled with solid PCM in the case of a circular tube $(A=0)$, while the amount of melted PCM is greater in the case of a petal-shaped cross-section. Similar to the effect of $\Lambda$, increasing $A$ enlarges the contact zone between the inner heated-tube and the surrounding PCM, which intensifies heat transfer and boosts PCM melting. 


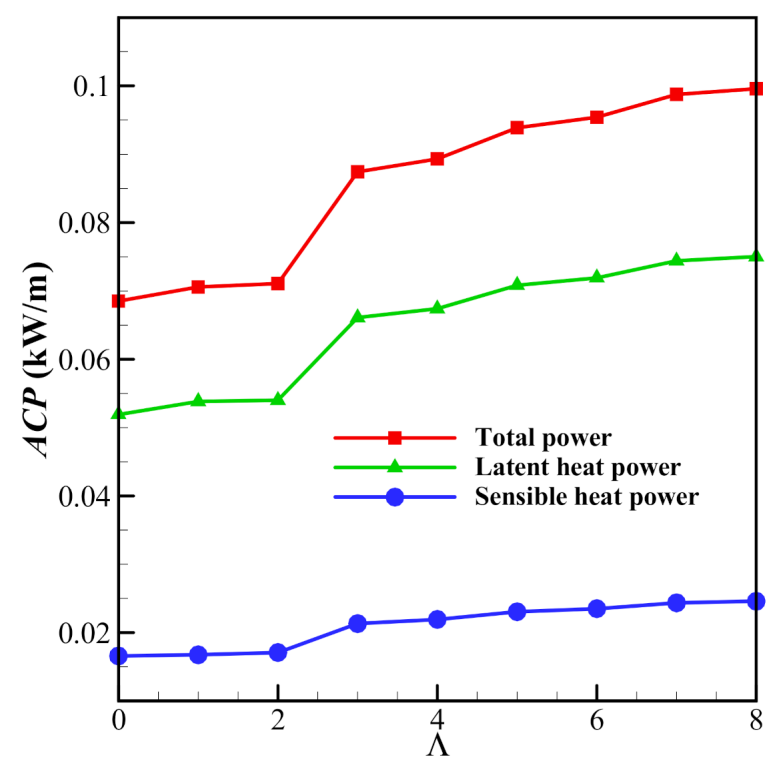

Figure 8. The average charging power $(\mathrm{kW} / \mathrm{m})$ based on the change in $\Lambda$ when $r_{d}=0.6 r_{s}$, $\omega_{C u}=0.04, \eta=\pi / 4$, and $A=0.15 r_{s}$.
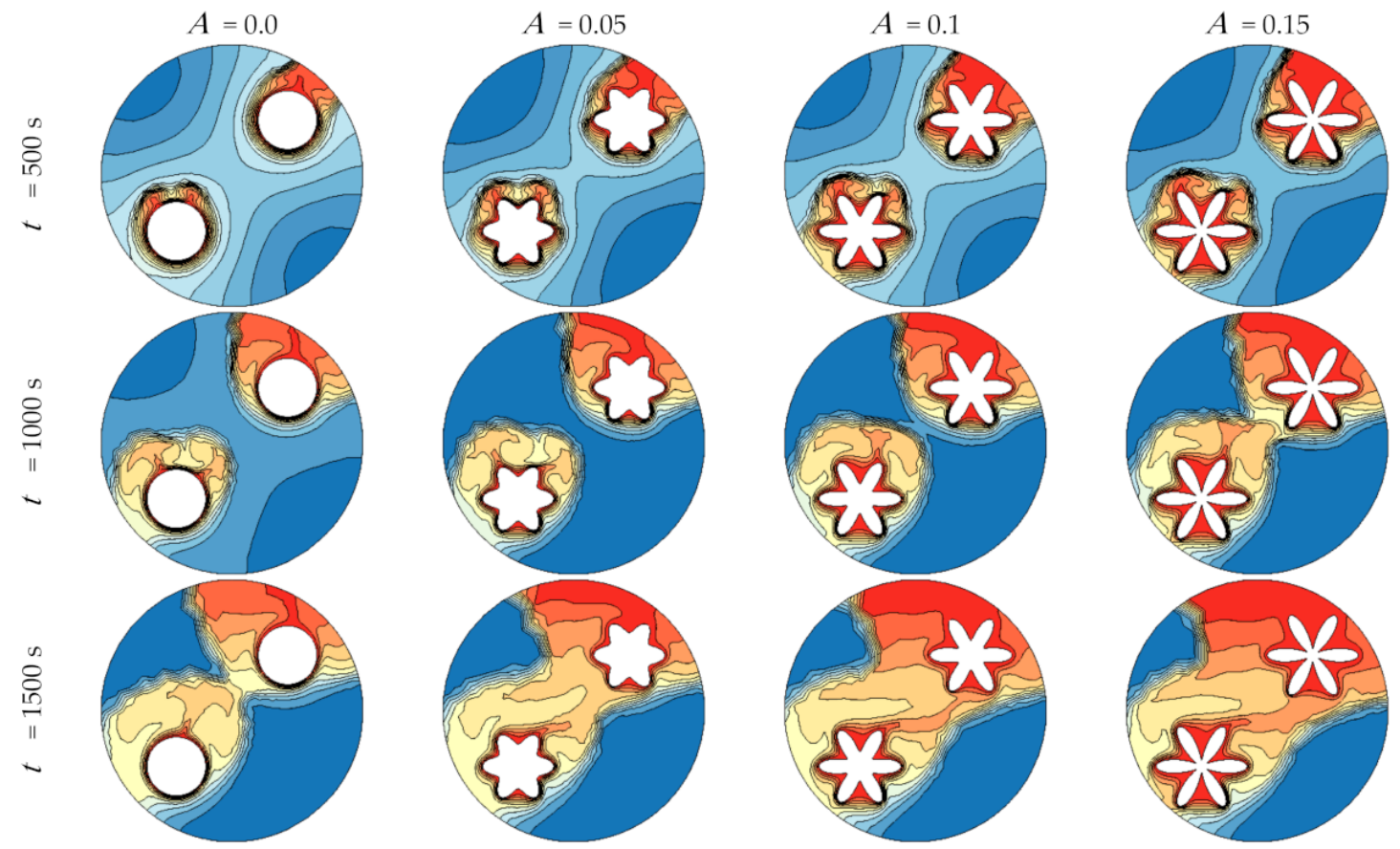

301302303304305306307308309310311312313314

$\mathbf{T}(\mathbf{K})$

Figure 9. The effect of $A$ on the isotherms at various charging times $\left(r_{d}=0.6 r_{s}, \omega_{C u}=0.04, \eta=\pi / 4, \Lambda=6\right)$.

The variations of MVF and ES as functions of time for various values of $A$ are shown in Figure 10. It can be seen that at every instant, MVF and ES are greater when $A$ is increased and are minimum for $A=0$. This indicates that the use of a petal-shaped inner tube improved PCM melting and increased the stored energy compared to a circular tube, and that such improvement can be further augmented by employing a higher petal amplitude. Figure 11 depicts the variation of ACP for different values of $A$. The energy stored rises when $A$ is increased. Simultaneously, the time required for full melting is reduced for 
higher values of $A$. For this reason, the ACP shows greater values when $A$ is increased. This result is due, as mentioned earlier, to the increased contact area between the PCM and the inner tube for higher $A$, which promotes heat transfer and enhances PCM melting. Raising $A$ from $0.05 r_{d}$ to $0.15 r_{d}$ can increase the total ACP by $26 \%$. Furthermore, the highest average charging power in latent and sensible heat power corresponds to $0.15 r_{\mathrm{d}}$.

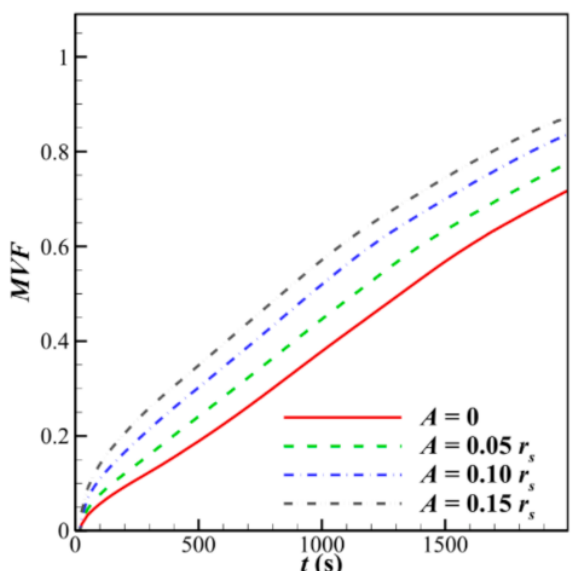

(a)

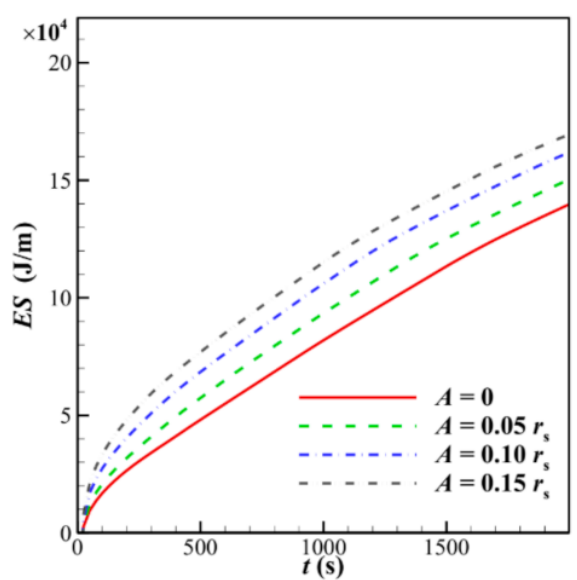

(b)

Figure 10. The variation of melting volume fraction (MVF) (a) and ES (J/m) (b) based on the change in $A$ when $r_{d}=0.6 r_{s}, \omega_{C u}=0.04, \eta=\pi / 4$, and $\Lambda=6$.

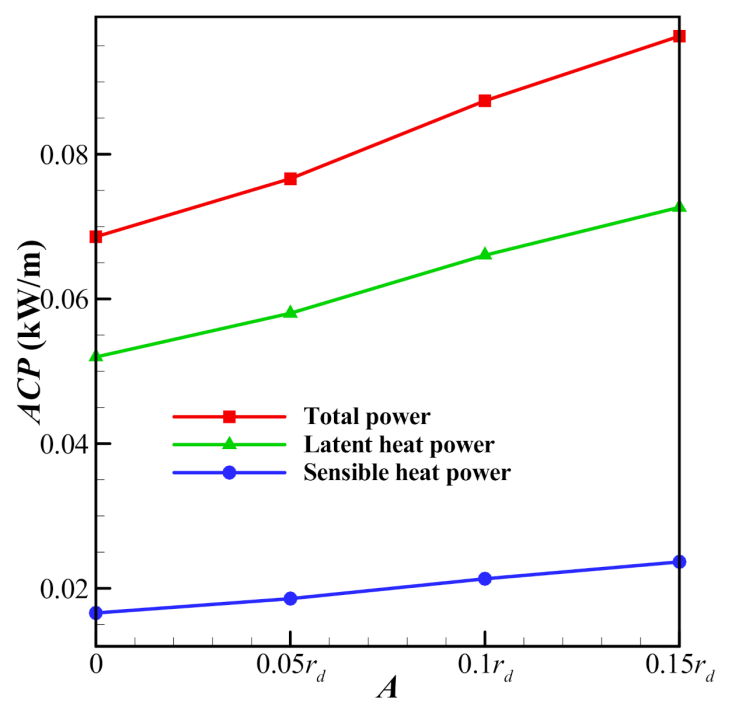

Figure 11. The average charging power (ACP) $(\mathrm{kW} / \mathrm{m})$ based on the change in $A$ when $r_{d}=0.6 r_{s}$, $\omega_{C u}=0.04, \eta=\pi / 4$, and $\Lambda=6$.

Figure 12 illustrates the streamlines and the isothermal contours for various values of the distance between the two branches of the inner pipe $r_{d}$. A higher value of $r_{d}$ shifts the inner pipe branches toward the shell of the exchanger, while a lower value moves them towards the center. For this reason, it can be seen that for lower $r_{d}$, PCM melting starts mainly in the central region of the cavity, while melting occurs mostly near the outer wall when $r_{d}$ is increased. As time goes, the zone of PCM melting increases in size in all the cases while remaining relatively away from the shell for low $r_{d}$. For $t=1000 \mathrm{~s}$, it can be seen that for $r_{d}=0.4 r_{s}$, some PCM remains in the solid-state near the shell, while for $r_{d}=0.6 r_{s}$, the PCM melts near the shell, but relatively more solid PCM remains in the central zone. The value of $r_{d}=0.5 r_{s}$ represents a balance between the two previous cases, as the PCM is 
evenly melted in the center and near the outer walls. Nevertheless, the PCM keeps melting with time, and at the end, the melted zones are close in size for all the values of $r_{d}$.
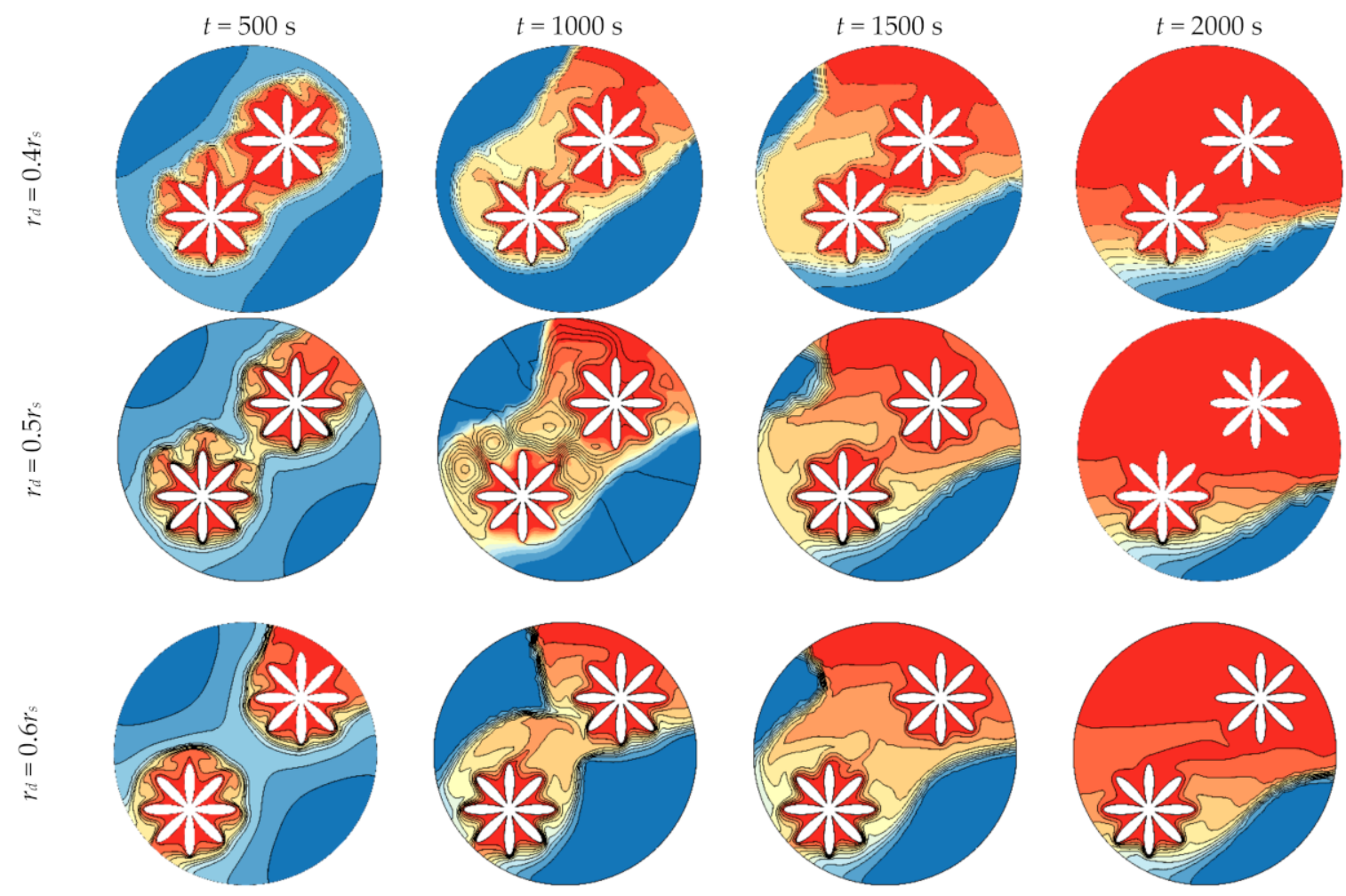

301302303304305306307308309310311312313314 T(K)

Figure 12. The effect of $r_{d}$ on the isotherms at various charging times $\left(\Lambda=8, \omega_{C u}=0.04, \eta=\pi / 4, A=0.15 r_{s}\right)$.

The variations of MVF and ES as functions of time are plotted in Figure 13 for different values of $r_{d}$. Initially, the variation is the same for all the values of $r_{d}$. Once the PCM starts melting, a slight increase of the MVF and the ES is observed for $r_{d}=0.5 r_{s}$ compared to the two other values. This is related to the observations of Figure 12, in which it was shown that the value of $r_{d}=0.5 r_{s}$ allows an even distribution of PCM melting in the central part and near the outer shell. This, consequently, increases the melting rate and the value of ES. Figure 14 shows the variation of ACP for different values of $r_{d}$. As ES and the melting rate are higher for $r_{d}=0.5 r_{s}$ compared to the other values, the ACP shows a maximum for $r_{d}=0.5 r_{s}$. However, the effect of $r_{d}$ on the ACP remains limited, as only a $4 \%$ increase in the total ACP can be obtained when $r_{d}$ is changed from $0.4 r_{s}$ to $0.5 r_{s}$.

The variations of MVF and ES as functions of time are shown in Figure 15 for various values of the volume fraction of $\mathrm{Cu}$ nanoparticles $\omega_{\mathrm{Cu}}$ and $\mathrm{GO}$ nanoparticles $\omega_{\mathrm{GO}}$. First, it can be seen that the variation of the MVF is almost the same for the same value of $\omega$, regardless of the type of nanoparticle. Second, the presence of nanoparticles, either $\mathrm{Cu}$ or GO, shows slightly higher values of MVF and ES compared to a pure fluid. This shows that the dispersion of nanoparticles in the PCM enhances heat transfer by improving the PCM thermal conductivity. A slight increase in the value of ES can also be observed when $\mathrm{Cu}$ nanoparticles are used instead of GO for the same value of $\omega$. The impact of $\omega_{\mathrm{Cu}}$ and $\omega_{\mathrm{GO}}$ on the variation of ACP is illustrated in Figure 16. The ACP increases with the rise of $\omega$ following the increase of the melting rate and ES. Moreover, the type of nanoparticles seems to have very little effect on the ACP. Using an $8 \%$ volume fraction of $\mathrm{Cu}$ and GO nanoparticles provides, respectively, an $11 \%$ and $7 \%$ rise in the total ACP compared to a pure fluid. Generally, the thermal conductivity and the volumetric heat capacity, i.e., 
$\rho C_{p}$, of the nanoparticles play important roles in the total ACP compared to a pure PCM. Although the thermal conductivity of the GO nanoparticles is more than that of the $\mathrm{Cu}$ nanoparticles, the volumetric heat capacity of the $\mathrm{Cu}$ nanoparticles is almost 2.65 times higher than that of the GO nanoparticles. Therefore, the $\mathrm{Cu}$ nanoparticles improve the ACP more than the GO nanoparticles.

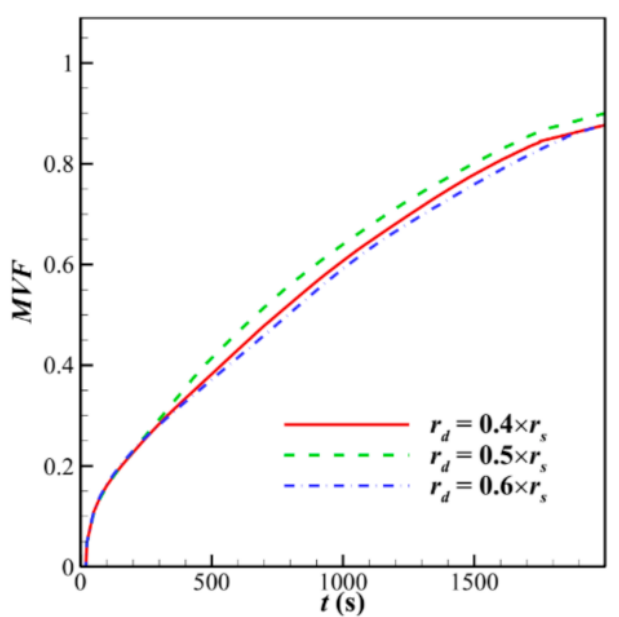

(a)

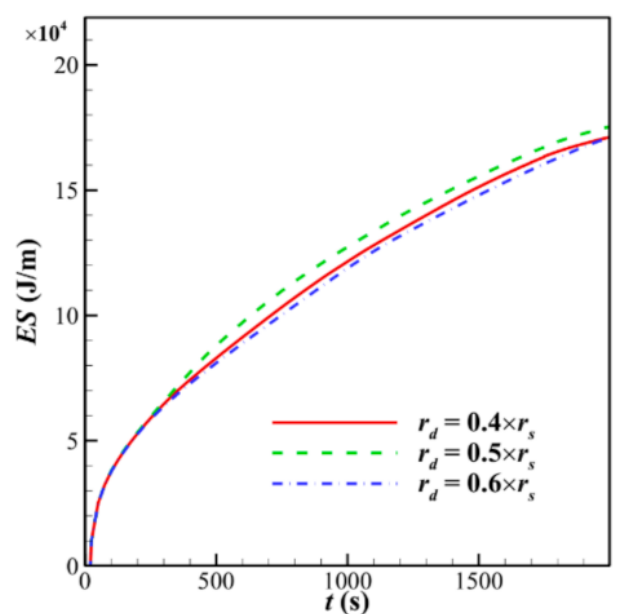

(b)

Figure 13. The variation of melting volume fraction (MVF) (a) and ES $(\mathrm{J} / \mathrm{m})(\mathbf{b})$ based on the change in $r_{d}$ when $\Lambda=8, \omega_{C u}=0.04, \eta=\pi / 4$, and $A=0.15 r_{s}$.

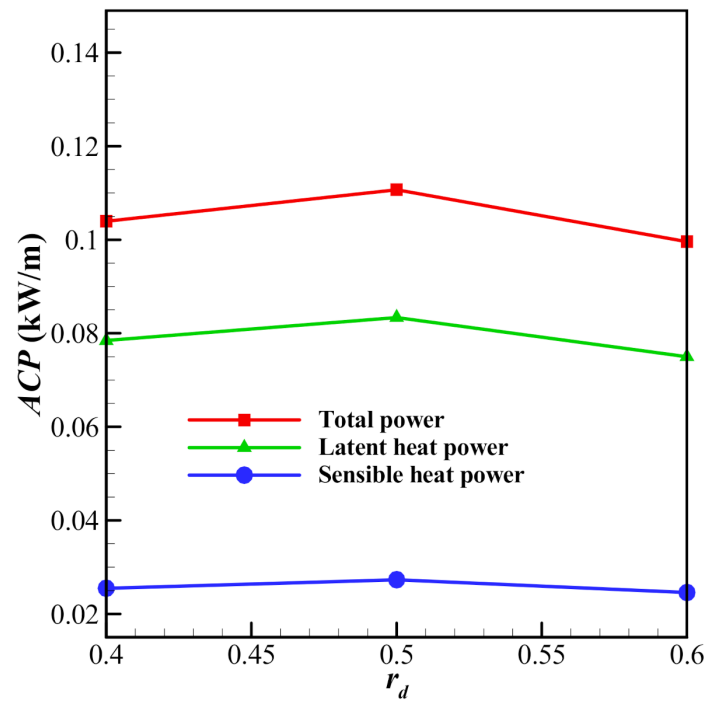

Figure 14. The average charging power $(\mathrm{kW} / \mathrm{m})$ based on the change in $r_{d}$ when $\Lambda=8, \omega_{C u}=0.04$, $\eta=\pi / 4$, and $A=0.15 r_{s}$. 


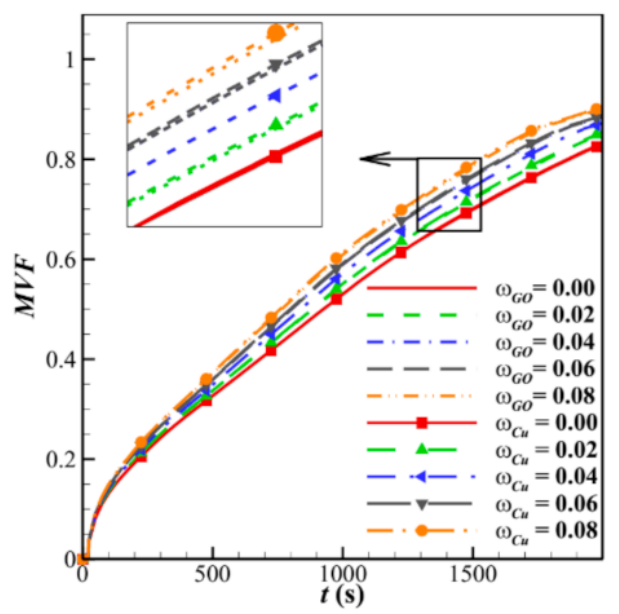

(a)

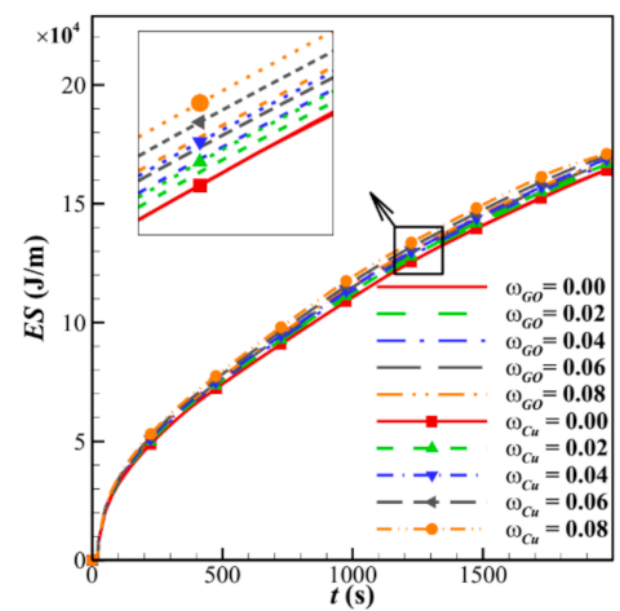

(b)

Figure 15. The variation of melting volume fraction (MVF) (a) and ES $(\mathrm{J} / \mathrm{m})(\mathbf{b})$ based on the change in $\omega_{C u}$ and $\omega_{G O}$ when $\Lambda=6, \eta=\pi / 4, A=0.15 r_{s}$, and $r_{d}=0.6 r_{s}$.

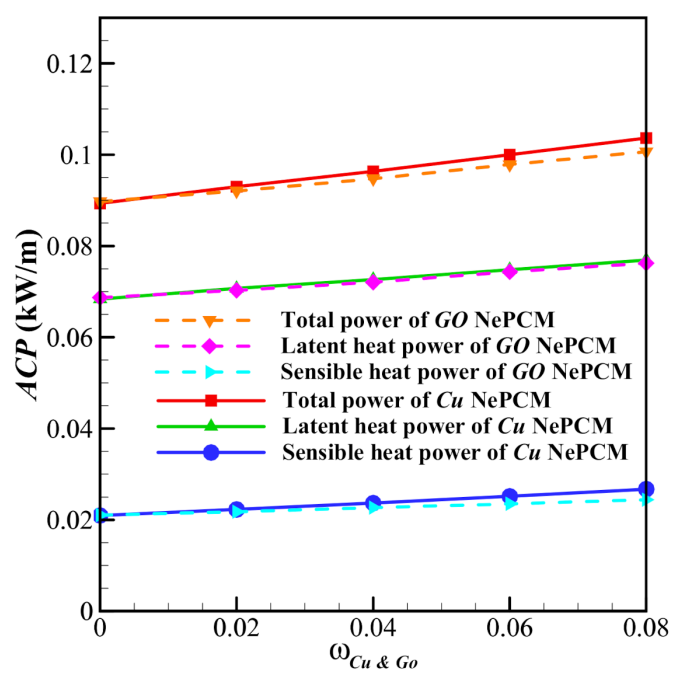

Figure 16. The average charging power $(\mathrm{kW} / \mathrm{m})$ based on the change in $\omega_{C u}$ and $\omega_{G O}$ when $\Lambda=6$, $\eta=\pi / 4, A=0.15 r_{s}$, and $r_{d}=0.6 r_{s}$.

The isotherms and the streamlines are shown in Figure 17 for various values of the inclination angle of the inner tube $\eta$. The main impact of $\eta$ appears once the PCM starts melting. Comparing the case of a horizontal tube $(\eta=0)$ to the case of a vertical one $(\eta=\pi / 2)$ reveals a change in the zone in which the PCM undergoes melting. For $\eta=0$, the bottom of the cavity and a small portion at the top remain filled by solid PCM, while for $\eta=\pi / 2$, the PCM melts in the top and bottom regions and remains solid in the left and right side of the bottom part of the cavity. 


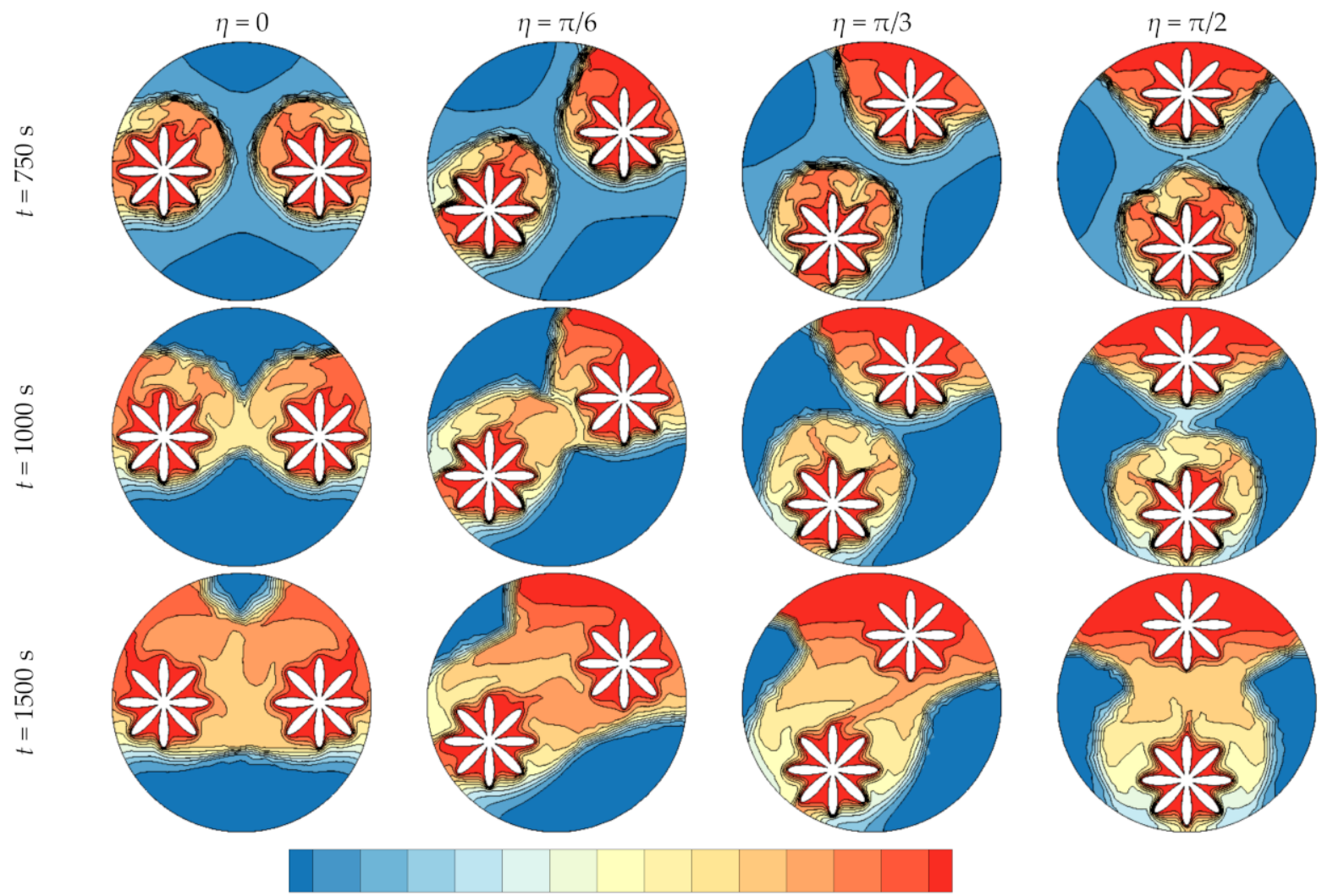

301302303304305306307308309310311312313314 T(K)

Figure 17. Effect of $\eta$ on the isotherms at various charging times $\left(\Lambda=8, r_{d}=0.6 r_{s}, \omega_{C u}=0.04, A=0.15 r_{s}\right)$.

Figure 18 depicts the variations of MVF and ES as functions of time for different values of $\eta$. It is shown that as time goes, the values of MVF and ES increase with $\eta$ and are maximum for $\eta=\pi / 2$. The gap between MVF and ES for $\eta=\pi / 2$ and $\eta=0$ becomes more important in the last stages when an important amount of PCM is already melted. In that case, the convective effects are more intensified in the case of a vertical tube where the heated PCM at the bottom moves upwards. This aspect is not present in the case of a horizontal tube as no PCM is heated in the bottom of the cavity and the convective effects are relatively diminished. The variation of ACP is plotted in Figure 19 for various values of $\eta$. A higher ACP is obtained when $\eta$ is raised, due to the increased melting rate and stored energy in that case. Using a vertical tube increases the total ACP by $5 \%$ compared to a horizontal one. 


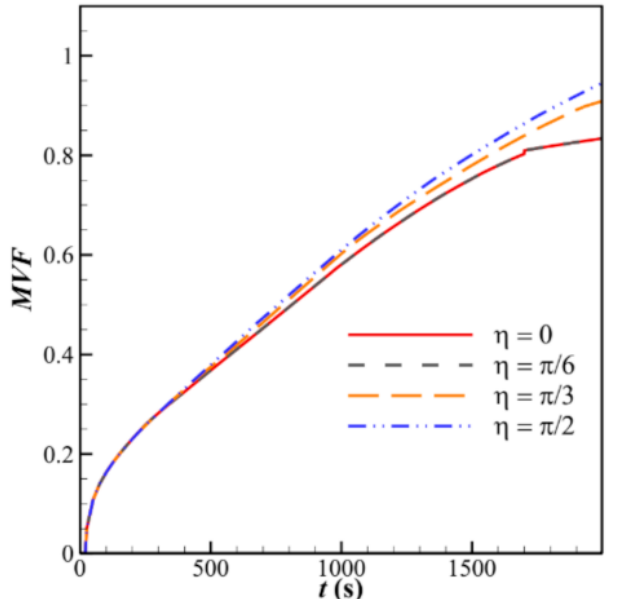

(a)

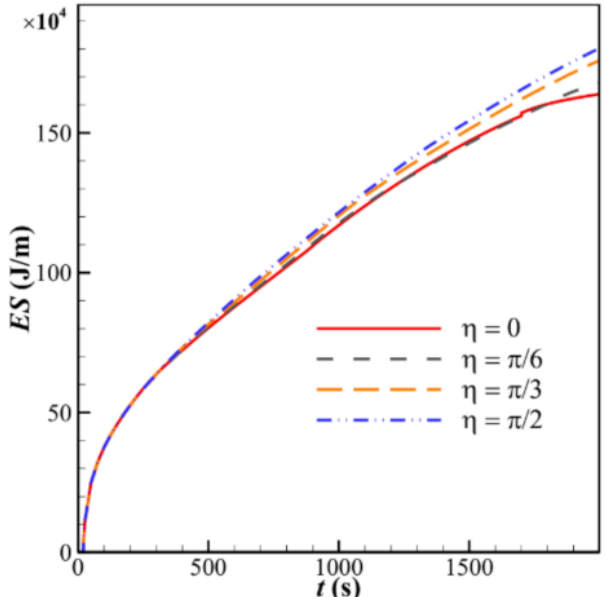

(b)

Figure 18. The variation of melting volume fraction (MVF) (a) and ES (J/m) (b) based on the change in $\eta$ when $\Lambda=8, \omega_{C u}=0.04, A=0.15 r_{s}, r_{d}=0.6 r_{s}$.

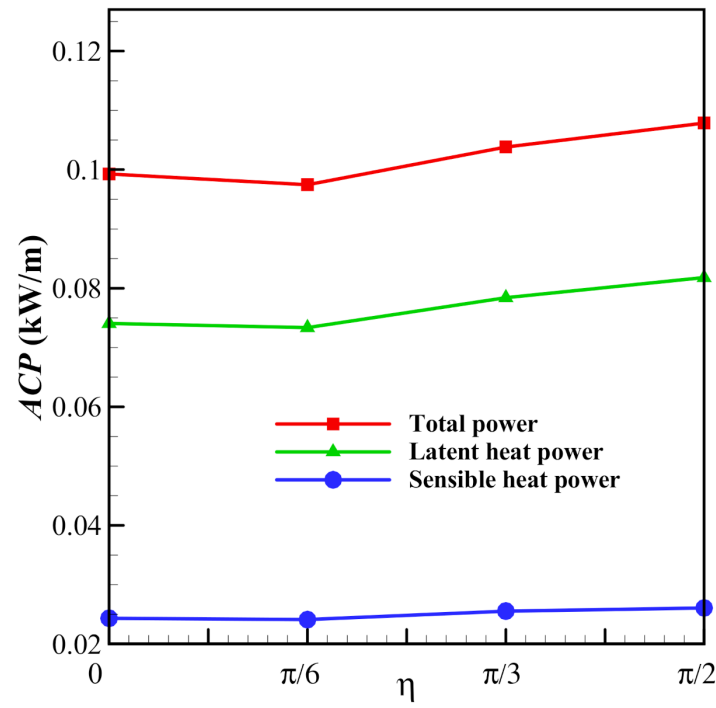

Figure 19. The average charging power $(\mathrm{kW} / \mathrm{m})$ based on the change $\eta$ when $\Lambda=8, \omega_{C u}=0.04$, $A=0.15 r_{s}, r_{d}=0.6 r_{s}$.

\section{Conclusions}

The impacts of the geometrical design of heat transfer tube with a petal shape and using nanoadditives on the energy storage rate and heat transfer of a thermal energy storage shell unit were investigated. The finite element method was applied to solve the phase change heat transfer equation along with natural convection flow. The mesh adaptation approach successfully followed the melting interface. The results were analyzed in the form of the time history of melting volume fraction and energy storage and the temperature distribution in the thermal energy storage unit. The main conclusions of the present investigation are the following:

- The cross-sectional shape of the inner tube is an important parameter in heat transfer and in the energy storage of the PCM. Using a petal-shaped tube instead of a circular one increases the surface contact between the tube and the surrounding PCM, which, consequently, intensifies heat transfer and enhances melting. This effect is further emphasized when the number of petals $\Lambda$ and/or their amplitude is increased. The average charging power can be increased by up to $45 \%$ when a petal-shaped tube with 
$\Lambda=8$ is used instead of a circular one, and by $26 \%$ when the amplitude of the petals is increased by 3 times.

- The distance between the two branches of the inner tube $r_{d}$ has a slight effect on the thermal and flow behaviors in the heat exchanger. Shifting the inner tube towards the center by reducing $r_{d}$ or towards the outer shell by raising $r_{d}$ limits the zone of PCM melting and diminishes energy storage. The optimal value for PCM melting and energy storage is $r_{d}=0.4 r_{s}$. Nonetheless, the impact of $0.4 r_{d}$ remains relatively limited. A $4 \%$ reduction in the charging power is observed when $r_{d}$ is increased from $0.4 r_{s}$ to $0.5 r_{s}$.

- The inclination angle of the inner tube impacts the convective effects in the cavity. Using a vertical tube instead of a horizontal one intensifies the convection of the melt and increases the stored energy. As a consequence, a vertical inner tube leads to a $5 \%$ increase in the charging power compared to a horizontal one.

- Dispersing conductive nanoparticles in the PCM increases its thermal conductivity, which improves its thermal transfer properties. However, the type of nanoparticles dispersed in the PCM has little effect on the melted volume and the stored energy, as similar results are obtained when either $\mathrm{Cu}$ or GO nanoparticles are used, with a little advantage for $\mathrm{Cu}$. On the other hand, raising the concentration of the nanoparticles enhances PCM melting and the corresponding stored energy. Using an $8 \%$ nanoparticle, the charging power can be raised by $7 \%$ for $\mathrm{GO}$ and $11 \%$ for $\mathrm{Cu}$ nanoparticles than a pure PCM.

The present study aimed to provide a means to model and investigate the thermal performance of NePCMs in a thermal energy storage design. The focus was mainly on the thermal aspect of NePCMs. However, there are many unknowns and uncertainties in applying NePCMs, such as durability, homogeneity, cost, and environmental aspects, that could be subject to future research.

Author Contributions: Conceptualization, S.A.M.M. and M.G.; methodology, S.A.M.M., A.H., O.Y., P.T., W.Y., and M.G.; software, R.K.F., S.A.M.M., and M.G.; validation, S.A.M.M. and M.G.; formal analysis, S.A.M.M., A.H., R.K.F., and O.Y.; investigation, S.A.M.M., R.K.F., A.H., P.T., O.Y., and W.Y.; resources, W.Y. and O.Y.; writing—original draft preparation, S.A.M.M., A.H., R.K.F., O.Y., P.T., W.Y., and M.G.; writing-review and editing, S.A.M.M., A.H., O.Y., P.T., W.Y., and M.G.; visualization, R.K.F. and S.A.M.M.; supervision, M.G.; funding acquisition, W.Y., O.Y., and M.G. All authors have read and agreed to the published version of the manuscript.

Funding: This research received no external funding.

Data Availability Statement: The data will be available on request.

Conflicts of Interest: The authors declare no conflict of interest.

\section{References}

1. Nižetić, S.; Jurčević, M.; Arıı, M.; Arasu, A.V.; Xie, G. Nano-enhanced phase change materials and fluids in energy applications: A review. Renew. Sustain. Energy Rev. 2020, 129, 109931. [CrossRef]

2. Reddy, K.; Mudgal, V.; Mallick, T. Review of latent heat thermal energy storage for improved material stability and effective load management. J. Energy Storage 2018, 15, 205-227. [CrossRef]

3. Li, Z.; Ma, T.; Zhao, J.; Song, A.; Cheng, Y. Experimental study and performance analysis on solar photovoltaic panel integrated with phase change material. Energy 2019, 178, 471-486. [CrossRef]

4. Zhang, Y.; Zhou, G.; Lin, K.; Zhang, Q.; Di, H. Application of latent heat thermal energy storage in buildings: State-of-the-art and outlook. Build. Environ. 2007, 42, 2197-2209. [CrossRef]

5. Cui, Y.; Xie, J.; Liu, J.; Wang, J.; Chen, S. A review on phase change material application in building. Adv. Mech. Eng. 2017, 9. [CrossRef]

6. Kong, X.; Jie, P.; Yao, C.; Liu, Y. Experimental study on thermal performance of phase change material passive and active combined using for building application in winter. Appl. Energy 2017, 206, 293-302. [CrossRef]

7. Abdolmaleki, L.; Sadrameli, S.; Pirvaram, A. Application of environmental friendly and eutectic phase change materials for the efficiency enhancement of household freezers. Renew. Energy 2020, 145, 233-241. [CrossRef]

8. Liang, S.; Tian, C.; Zhu, Y.; Gu, Y.; Chen, K.; Wang, J. Phase-Change Energy-Storage Material Nanocapsule and Preparation Method Thereof. CN104449590A, 25 March 2015. 
9. Wang, X.; Jiang, F.; Wu, D. Magnetic Microencapsulated Phase Change Energy Storage Material and Preparation Method Thereof. CN103992774A, 20 August 2014.

10. Li, Y.; Wang, F. High Temperature Resistant Type Phase-Change Material Micro-Capsule and Preparation Thereof. CN101376800B, 9 February 2011.

11. Wang, J.; Xie, H.; Li, Y. Paraffinic Based Carbon Nano-Tube Compound Phase Transformation Heat Accumulating Material and Preparation Thereof. CN101407714A, 15 April 2009.

12. Christ, M.U.; Ottinger, O.H.; Bacher, J.J. Latent Heat Storage Material and Process for Manufacture of the Latent Heat Storage Material. U.S. Patent US7923112B2, 12 April 2011.

13. White, M.; Brehm, P. Systems, Apparatus and Methods for Thermal Energy Storage, Coupling and Transfer. U.S. Patent US8464535B2, 18 June 2013.

14. Ho, C.; Gao, J. An experimental study on melting heat transfer of paraffin dispersed with $\mathrm{Al}_{2} \mathrm{O}_{3}$ nanoparticles in a vertical enclosure. Int. J. Heat Mass Transf. 2013, 62, 2-8. [CrossRef]

15. Dhaidan, N.S.; Khodadadi, J.; Al-Hattab, T.A.; Al-Mashat, S.M. Experimental and numerical investigation of melting of phase change material/nanoparticle suspensions in a square container subjected to a constant heat flux. Int. J. Heat Mass Transf. 2013, 66, 672-683. [CrossRef]

16. Zeng, Y.; Fan, L.-W.; Xiao, Y.-Q.; Yu, Z.-T.; Cen, K.-F. An experimental investigation of melting of nanoparticle-enhanced phase change materials (NePCMs) in a bottom-heated vertical cylindrical cavity. Int. J. Heat Mass Transf. 2013, 66, 111-117. [CrossRef]

17. Li, Z.-R.; Hu, N.; Liu, J.; Zhang, R.-H.; Fan, L.-W. Revisiting melting heat transfer of nano-enhanced phase change materials (NePCM) in differentially-heated rectangular cavities using thermochromic liquid crystal (TLC) thermography. Int. J. Heat Mass Transf. 2020, 159, 120119. [CrossRef]

18. Parsazadeh, M.; Duan, X. Numerical and statistical study on melting of nanoparticle enhanced phase change material in a shell-and-tube thermal energy storage system. Appl. Therm. Eng. 2017, 111, 950-960. [CrossRef]

19. Hosseinizadeh, S.; Darzi, A.R.; Tan, F. Numerical investigations of unconstrained melting of nano-enhanced phase change material (NEPCM) inside a spherical container. Int. J. Therm. Sci. 2012, 51, 77-83. [CrossRef]

20. Zhang, S.; Zhang, X.; Xu, X.; Zhao, Y. Experimental study on the storage and release characteristics of phase change materials with different nanomaterials as addictives. Heat Mass Transf. 2020, 56, 2769-2777. [CrossRef]

21. Ji, C.; Qin, Z.; Low, Z.; Dubey, S.; Choo, F.H.; Duan, F. Non-uniform heat transfer suppression to enhance PCM melting by angled fins. Appl. Therm. Eng. 2018, 129, 269-279. [CrossRef]

22. Xie, J.; Lee, H.M.; Xiang, J. Numerical study of thermally optimized metal structures in a Phase Change Material (PCM) enclosure. Appl. Therm. Eng. 2019, 148, 825-837. [CrossRef]

23. Mostafavi, A.; Parhizi, M.; Jain, A. Semi-analytical thermal modeling of transverse and longitudinal fins in a cylindrical phase change energy storage system. Int. J. Therm. Sci. 2020, 153, 106352. [CrossRef]

24. Pourakabar, A.; Darzi, A.A.R. Enhancement of phase change rate of PCM in cylindrical thermal energy storage. Appl. Therm. Eng. 2019, 150, 132-142. [CrossRef]

25. Sheikholeslami, M. Numerical modeling of nano enhanced PCM solidification in an enclosure with metallic fin. J. Mol. Liq. 2018, 259, 424-438. [CrossRef]

26. Nguyen-Thoi, T.; Bhatti, M.; Ali, J.A.; Hamad, S.M.; Sheikholeslami, M.; Shafee, A.; Haq, R.U. Analysis on the heat storage unit through a Y-shaped fin for solidification of NEPCM. J. Mol. Liq. 2019, 292, 111378. [CrossRef]

27. Sheikholeslami, M.; Jafaryar, M.; Shafee, A.; Li, Z. Simulation of nanoparticles application for expediting melting of PCM inside a finned enclosure. Phys. A Stat. Mech. Appl. 2019, 523, 544-556. [CrossRef]

28. Mahdi, J.M.; Lohrasbi, S.; Ganji, D.D.; Nsofor, E.C. Simultaneous energy storage and recovery in the triplex-tube heat exchanger with PCM, copper fins and $\mathrm{Al}_{2} \mathrm{O}_{3}$ nanoparticles. Energy Convers. Manag. 2019, 180, 949-961. [CrossRef]

29. Zhang, X.; Sheikholeslami, M.; Yan, W.-M.; Shafee, A.; Selimefendigil, F.; Babazadeh, H. Energy storage analysis for discharging of nanoparticle enhanced phase change material within a triplex-tube thermal storage. J. Energy Storage 2020, 31, 101640. [CrossRef]

30. Alizadeh, M.; Hosseinzadeh, K.; Mehrzadi, H.; Ganji, D. Investigation of LHTESS filled by Hybrid nano-enhanced PCM with Koch snowflake fractal cross section in the presence of thermal radiation. J. Mol. Liq. 2019, 273, 414-424. [CrossRef]

31. Sheikholeslami, M.; Haq, R.-U.; Shafee, A.; Li, Z. Heat transfer behavior of nanoparticle enhanced PCM solidification through an enclosure with V shaped fins. Int. J. Heat Mass Transf. 2019, 130, 1322-1342. [CrossRef]

32. Li, Z.; Sheikholeslami, M.; Ayani, M.; Shamlooei, M.; Shafee, A.; Waly, M.I.; Tlili, I. Acceleration of solidification process by means of nanoparticles in an energy storage enclosure using numerical approach. Phys. A Stat. Mech. Appl. 2019, 524, 540-552. [CrossRef]

33. Sheikholeslami, M. Numerical simulation for solidification in a LHTESS by means of nano-enhanced PCM. J. Taiwan Inst. Chem. Eng. 2018, 86, 25-41. [CrossRef]

34. Tariq, S.L.; Ali, H.M.; Akram, M.A.; Janjua, M.M.; Ahmadlouydarab, M. Nanoparticles enhanced phase change materials (NePCMs)-A recent review. Appl. Therm. Eng. 2020, 115305. [CrossRef]

35. Hussanan, A.; Salleh, M.Z.; Khan, I.; Shafie, S. Convection heat transfer in micropolar nanofluids with oxide nanoparticles in water, kerosene and engine oil. J. Mol. Liq. 2017, 229, 482-488. [CrossRef]

36. Kant, K.; Shukla, A.; Sharma, A.; Biwole, P.H. Heat transfer study of phase change materials with graphene nano particle for thermal energy storage. Sol. Energy 2017, 146, 453-463. [CrossRef] 
37. Nield, D.A.; Bejan, A. Convection in Porous Media; Springer Science \& Business Media: Berlin, Germany, 2006.

38. Buongiorno, J. Convective transport in nanofluids. J. Heat Transf. 2006, 128, 240-250. [CrossRef]

39. Sheikholeslami, M.; Shamlooei, M.; Moradi, $\mathrm{R}$. $\mathrm{Fe}_{3} \mathrm{O}_{4}$-Ethylene glycol nanofluid forced convection inside a porous enclosure in existence of Coulomb force. J. Mol. Liq. 2018, 249, 429-437. [CrossRef]

40. Selvaraj, V.; Morri, B.; Nair, L.M.; Krishnan, H. Experimental investigation on the thermophysical properties of beryllium oxide-based nanofluid and nano-enhanced phase change material. J. Therm. Anal. Calorim. 2019, 137, 1527-1536. [CrossRef]

41. Reddy, J.N.; Gartling, D.K. The Finite Element Method in Heat Transfer and Fluid Dynamics; CRC Press: Boca Raton, FL, USA, 2010.

42. Zienkiewicz, O.C.; Taylor, R.L.; Nithiarasu, P. The Finite Element Method for Fluid Dynamics; Elsevier: Amsterdam, The Netherlands, 2015; Volume 6.

43. De Los Reyes, J.C.; González Andrade, S. A combined BDF-semismooth Newton approach for time-dependent Bingham flow. Numer. Methods Partial Differ. Equ. 2012, 28, 834-860. [CrossRef]

44. Schenk, O.; Gärtner, K. Solving unsymmetric sparse systems of linear equations with PARDISO. Future Gener. Comput. Syst. 2004, 20, 475-487. [CrossRef]

45. Wriggers, P. Nonlinear Finite Element Methods; Springer Science \& Business Media: Berlin, Germany, 2008.

46. Verbosio, F.; De Coninck, A.; Kourounis, D.; Schenk, O. Enhancing the scalability of selected inversion factorization algorithms in genomic prediction. J. Comput. Sci. 2017, 22, 99-108. [CrossRef]

47. Kumar, L.; Manjunath, B.S.; Patel, R.J.; Markandeya, S.G.; Agrawal, R.G.; Agrawal, A.; Kashyap, Y.; Sarkar, P.S.; Sinha, A.; Iyer, K.N.; et al. Experimental investigations on melting of lead in a cuboid with constant heat flux boundary condition using thermal neutron radiography. Int. J. Therm. Sci. 2012, 61, 15-27. [CrossRef]

48. Bertrand, O.; Binet, B.; Combeau, H.; Couturier, S.; Delannoy, Y.; Gobin, D.; Lacroix, M.; Le Quéré, P.; Médale, M.; Mencinger, J.; et al. Melting driven by natural convection A comparison exercise: First results. Int. J. Therm. Sci. 1999, 38, 5-26. [CrossRef]

49. Gau, C.; Viskanta, R. Melting and solidification of a pure metal on a vertical wall. J. Heat Transfer. 1986, 108, 174-181. [CrossRef]

50. Brent, A.; Voller, V.R.; Reid, K. Enthalpy-porosity technique for modeling convection-diffusion phase change: Application to the melting of a pure metal. Numer. Heat Transf. Part A Appl. 1988, 13, 297-318.

51. Kashani, S.; Ranjbar, A.; Abdollahzadeh, M.; Sebti, S. Solidification of nano-enhanced phase change material (NEPCM) in a wavy cavity. Heat Mass Transf. 2012, 48, 1155-1166. [CrossRef]

52. Kuehn, T.H.; Goldstein, R.J. An experimental and theoretical study of natural convection in the annulus between horizontal concentric cylinders. J. Fluid Mech. 1976, 74, 695. [CrossRef] 